\title{
C-reactive protein promotes acute renal inflammation and fibrosis in unilateral ureteral obstructive nephropathy in mice
}

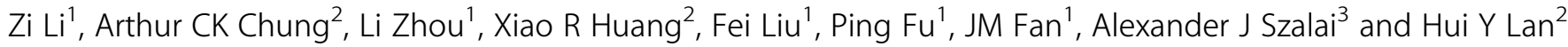

Elevated blood level of C-reactive protein (CRP) is associated with increased risk of chronic kidney disease. However, whether this association reflects functional importance of CRP in the pathogenesis of kidney disease remains unclear. In this study, we examined the biological role of CRP in a well-characterized model of progressive kidney disease, unilateral ureteral obstruction (UUO), in mice that express the human CRP gene (CRPtg). Compared with wild-type (Wt) mice at 3 days after UUO, CRPtg mice developed more severe renal inflammation with a significant increase in tubulointerstitial T cells and macrophages, upregulation of proinflammatory cytokines (IL-1 $\beta$ and TNF- $\alpha$ ), chemokines (MCP-1), and adhesion molecules (ICAM-1). Renal fibrosis was also significantly enhanced in CRPtg mice as demonstrated by increased expression of tubulointerstitial $\alpha$-smooth muscle actin and collagen types I and III compared with Wt mice. Interestingly, on days 7 and 14 after UUO, an equal severity of renal inflammation and fibrosis were observed in CRPtg and Wt mice. These findings suggested that CRP may have a role in the initiation of renal inflammation and fibrosis. Further study revealed that enhanced early renal inflammation and fibrosis on day 3 in CRPtg mice was associated with a significant upregulation of endogenous mouse CRP and Fc $\gamma$ RI mRNA and increased activation of both NF- $\kappa \mathrm{B} / \mathrm{p} 65$ and TGF- $\beta / \mathrm{Smad} 2 /$ 3 signaling, while equal severity of progressive renal injury at day 7 and day 14 between CRPtg and Wt mice were attributed to equivalent levels of CRP, Fc $\gamma \mathrm{Rl}$, phospho-NF- $\kappa \mathrm{B} / \mathrm{p} 65$, and TGF- $\beta / \mathrm{Smad} 2 / 3$ signaling. Based on these findings, we conclude that CRP may not only be a biomarker, but also a mediator in the early development of renal inflammation and fibrosis in a mouse model of UUO. Enhanced activation of both NF- $\kappa$ B and TGF- $\beta /$ Smad signaling pathways may be mechanisms by which CRP promotes early renal inflammation and fibrosis.

Laboratory Investigation (2011) 91, 837-851; doi:10.1038/labinvest.2011.42; published online 7 March 2011

KEYWORDS: CRP; NF- $\kappa$ B; renal fibrosis and inflammation; TGF- $\beta /$ Smad; UUO

Inflammation is prevalent in patients with chronic kidney disease $(\mathrm{CKD})$ and worsens as the CKD progresses toward end-stage renal disease (ESRD). ${ }^{1-3}$ Chronic inflammatory states in CKD patients are associated with elevated levels of serum acute phase proteins, including C-reactive protein (CRP).${ }^{1-3}$ CRP is rapidly synthesized by the liver in response to infection, inflammation, and tissue damage. ${ }^{4}$ Currently, CRP serves as one of the most important inflammatory marker in many chronic diseases, including CKD, diabetes, and major cardiovascular diseases. ${ }^{1-3,5,6}$ Increasing evidence also suggests that CRP may act as an inflammatory mediator during artherogenesis and thrombosis. ${ }^{7-9}$ CRP activates endothelial cells to express adhesion molecules, such as intercellular adhesion molecule-1 (ICAM-1), vascular cell adhesion molecule-1, and E-selectin. ${ }^{10-12}$ CRP has significant effects on monocytes and macrophages and induces expression of monocyte chemoattractant protein-1 (MCP-1). ${ }^{13,14}$ Most recently, we also demonstrated that CRP exacerbates hypertensive cardiac remodeling under high angiotensin II conditions. $^{15}$

Although many studies have shown that CRP is increased with declining renal function in CKD, even before ESRD, ${ }^{16-19}$ a pathogenic role of CRP in the development of CKD remains unproven. Thus, whether CRP is solely a biomarker

\footnotetext{
${ }^{1}$ Department of Medicine-Nephrology, West China Hospital of Sichuan University, Chengdu, China; ${ }^{2}$ Department of Medicine and Therapeutics, Li Ka Shing Institute of Health Sciences, The Chinese University of Hong Kong, Hong Kong, China and ${ }^{3}$ Department of Medicine, The University of Alabama at Birmingham, Birmingham, AL, USA

Correspondence: Dr HY Lan, MD, PhD, Department of Medicine and Therapeutics, Li Ka Shing Institute of Health Sciences, The Chinese University of Hong Kong, Prince of Wales Hospital, Shatin, The New Territories, Hong Kong, China.

E-mail: hylan@cuhk.edu.hk

Received 27 April 2010; revised 15 November 2010; accepted 25 November 2010
} 
Wt
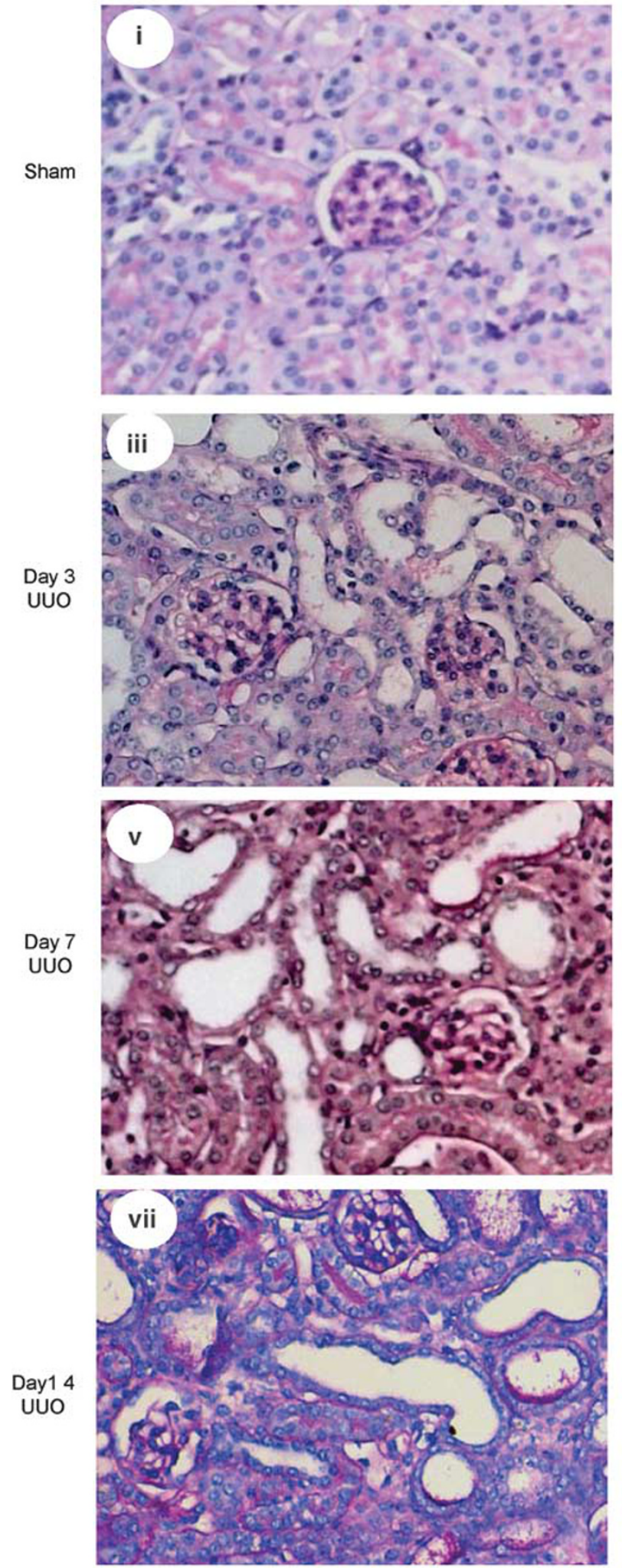

CRPtg
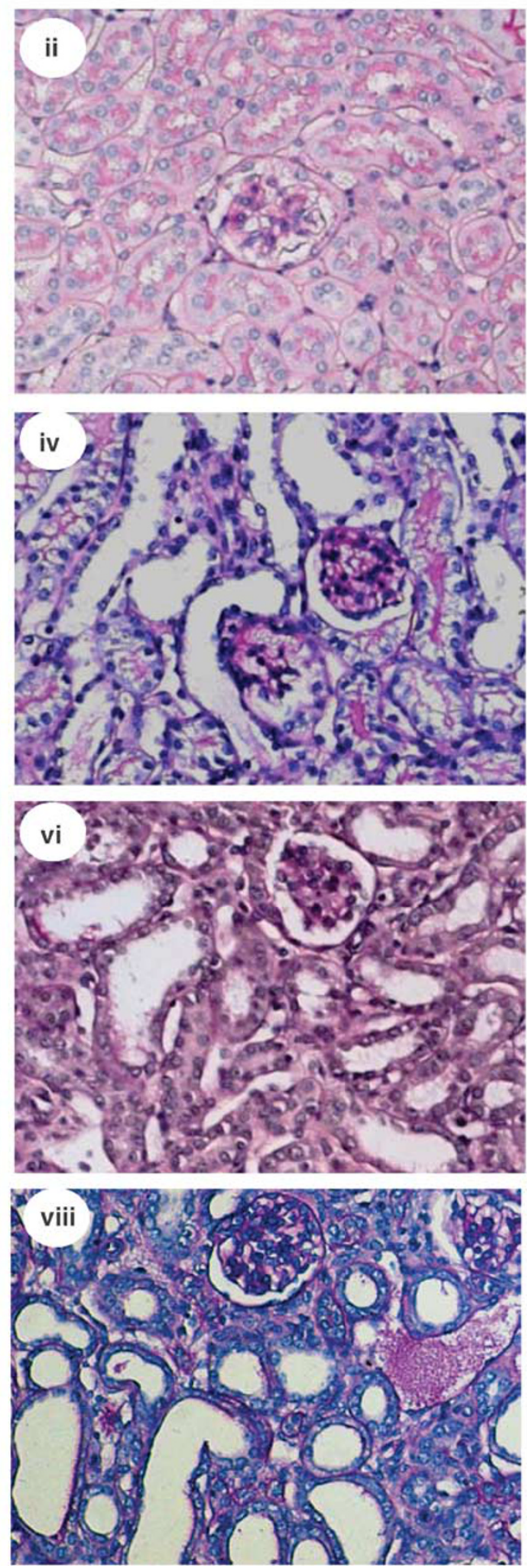

Figure 1 Representative cross-sections of mouse kidneys showing that expression of human CRP hastens renal injury after UUO. Three days after sham surgery kidneys from both Wt (i) and CRPtg (ii) appeared normal renal histology. In contrast, by day 3 after UUO, renal damage was more severe in CRPtg (iv) than Wt (iii). By day 7 and day 14, renal damage was of equal severity in both strains ( $v$-viii). Each PAS-stained tissue section represents for a group of at least six animals. Magnification $\times 200$. 
a
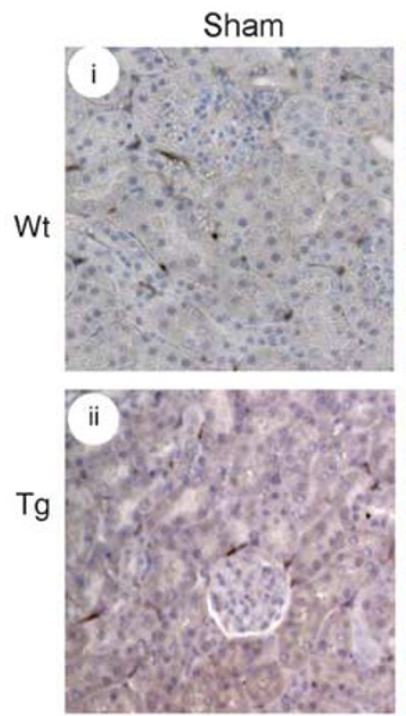

b
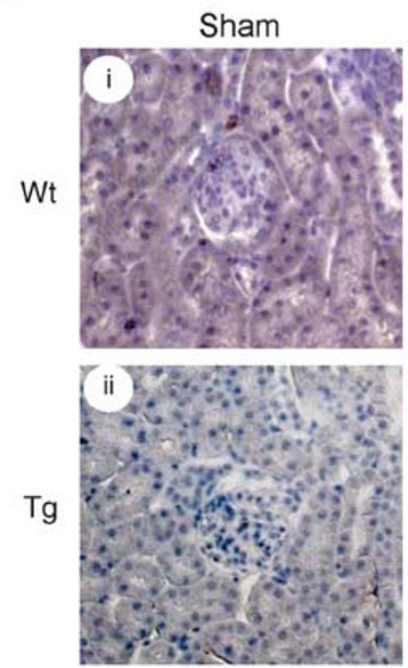

C
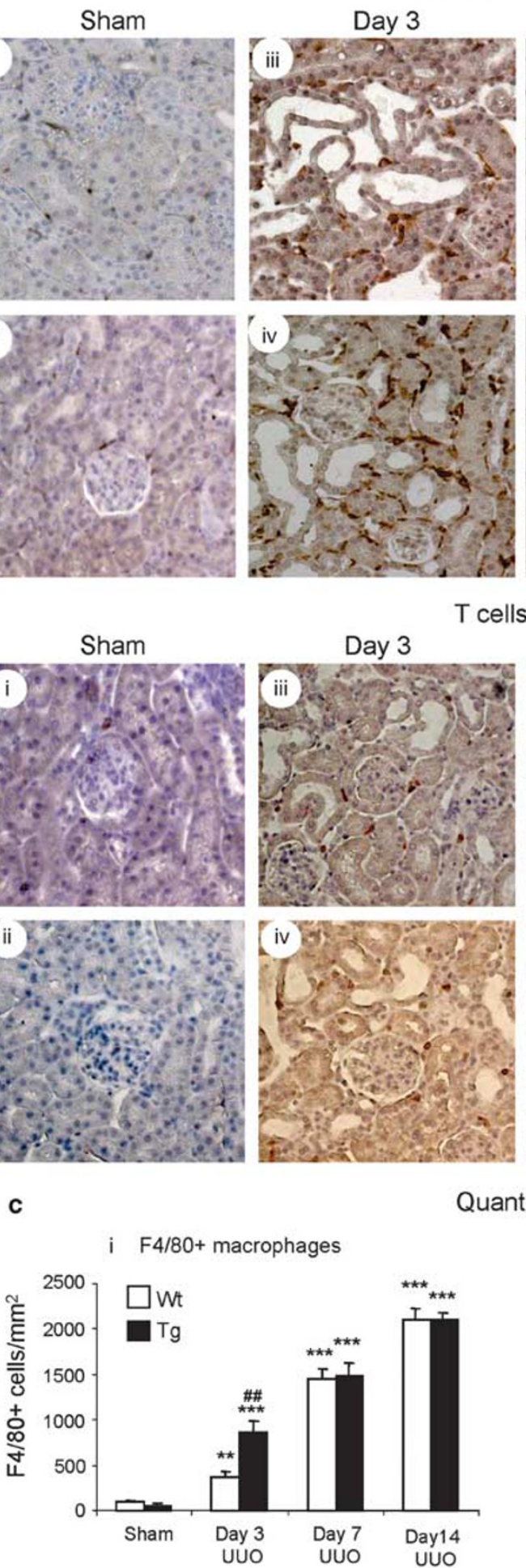

Macrophages

Day 7

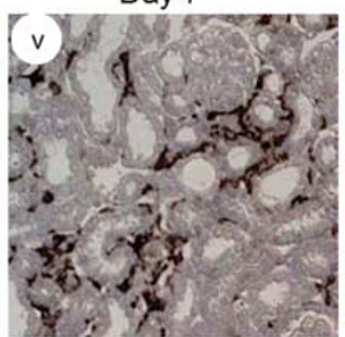

Day 14
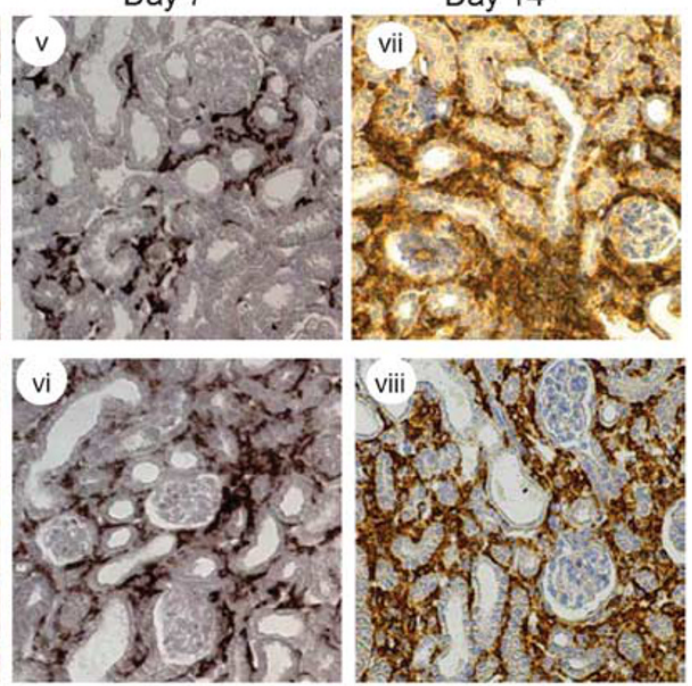

$\mathrm{T}$ cells
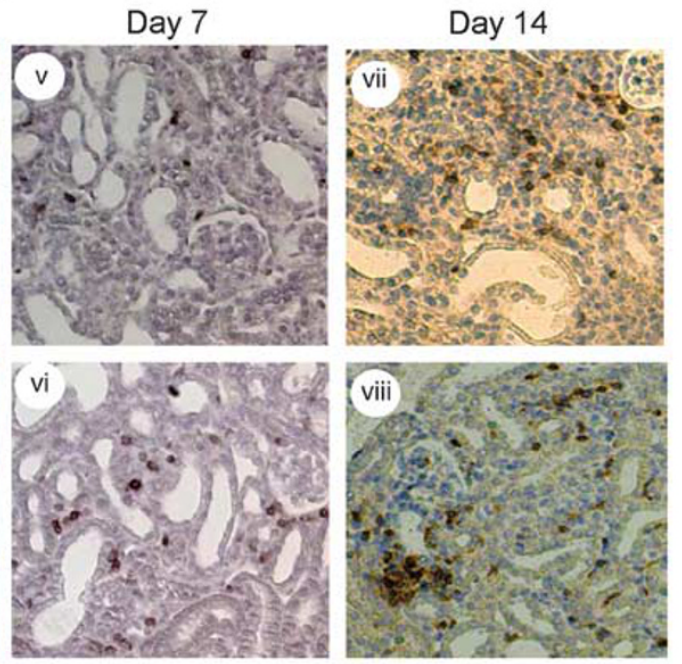

Quantitation

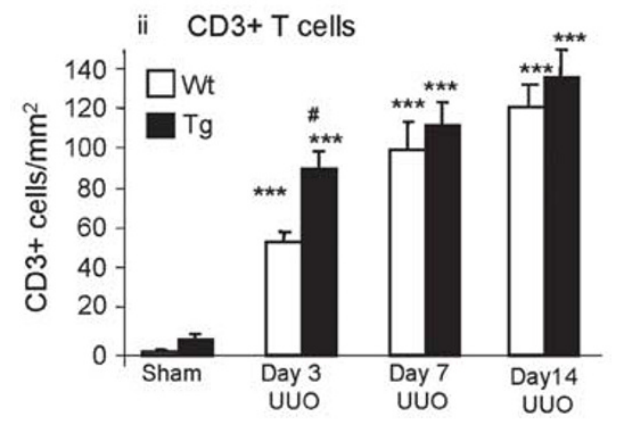

Figure 2 Immunohistochemistry reveals that overexpression of CRP enhances F4/80 + macrophage and CD3 + T-cell infiltration in the UUO kidney. (a) F4/80 + macrophage infiltration. (b) CD3 + T-cell infiltration. (i) A normal kidney from shamed Wt mouse, (ii) a normal kidney from shamed CRPtg mouse, (iii) a UUO kidney from a Wt mouse at day 3 after UUO, (iv) a UUO kidney from a CRPtg mouse at day 3 after UUO, (v) a UUO kidney from a Wt mouse at day 7 after UUO, (vi) a UUO kidney from a CRPtg mouse at day 7 after UUO, (vii) a UUO kidney from a Wt mouse at day 14 after UUO, (viii) a UUO kidney from a CRPtg mouse at day 14 after UUO. (c) Quantitative analysis. Note that F4/80 + macrophages and CD3 + T cells infiltrating the tubulointerstitium in the UUO kidney are further increased in CRPtg mice at day 3 after UUO. Sections were counterstained with hematoxylin. Each bar represents the mean \pm s.e.m. for at least six mice. ${ }^{* * *} P<0.001$ compared with the shamed control mice. ${ }^{\#} P<0.05 ;{ }^{\# \#} P<0.01$ as compared with the time-matched Wt UUO. Magnification $\times 200$. 
or also a mediator of the pathogenesis of CKD remains an unanswered question. In the present study, we sought an answer to this question using a CRP transgenic mouse (CRPtg) model of unilateral ureteral obstruction (UUO).

\section{MATERIALS AND METHODS CRP Transgenic Mice}

Ten- to 12-week-old male CRPtg and wild type (Wt) (littermates with a C57BL/6J background, 20-25 g) were used for this study. Characterization of CRPtg mice have been described previously and CRPtg mice were identified by genotyping of tail DNA with primers. ${ }^{20}$ In healthy male CRPtg mice, human CRP is generally present in the blood at concentrations of $3-10 \mu \mathrm{g} / \mathrm{ml}$ but at high levels ( $>500 \mu \mathrm{g} /$ $\mathrm{ml}$ ) during an endotoxemia or infection-induced acute phase response. ${ }^{4,21}$

\section{Obstructive Kidney Disease Model}

Progressive kidney disease was induced in CRPtg and agematched congenic Wt mice by left ureteral ligation (UUO) as described previously. ${ }^{22-24}$ In order to examine the pathogenic role of CRP in the initiation and progression of kidney injury, groups of $8 \mathrm{CRPtg}$ mice and $8 \mathrm{Wt}$ mice were killed on days 3,7 , and 14 after ureteral ligation. As controls, additional groups of age-matched CRPtg and Wt mice (six each) were killed on each time point on days 3, 7, and 14 after sham surgery. Kidney tissues were collected and prepared for histology, immunohistochemistry, western blotting, and realtime polymerase chain reaction (PCR) analyses. Blood was drawn from the left ventricle before kill and serum was collected. Serum human CRP levels were quantitatively analyzed using a human CRP Quantikine ELISA kit (R\&D System, Minneapolis, MN, USA), according to the manufacturer's a
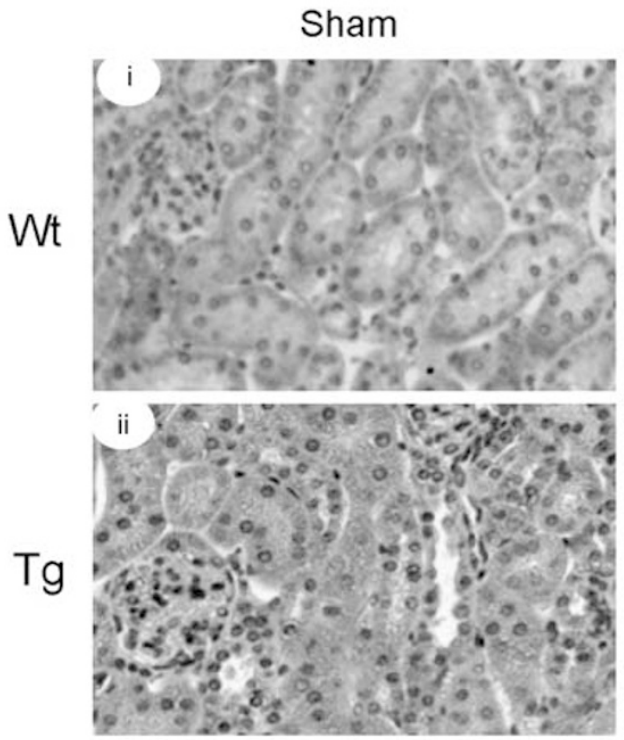

vii Quantitation of TNF $\alpha$

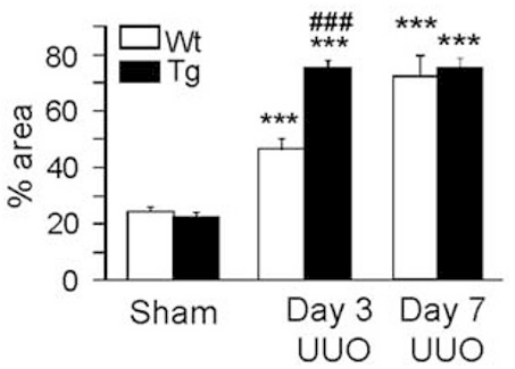

TNF- $\alpha$ expression

Day 3

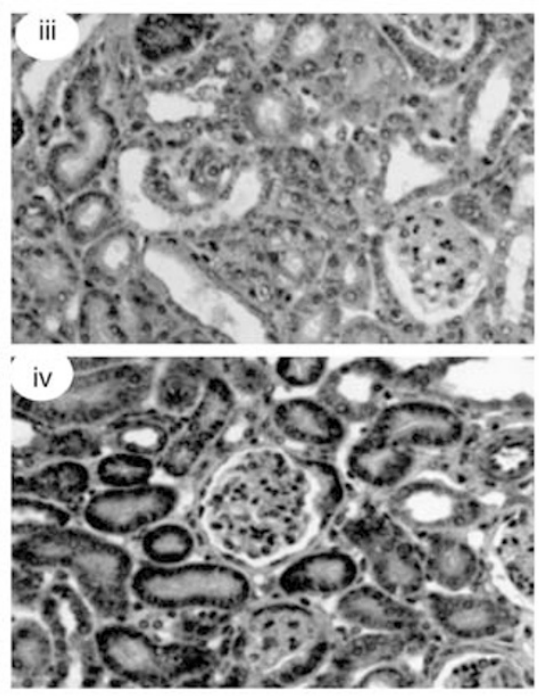

viii TNF-a mRNA

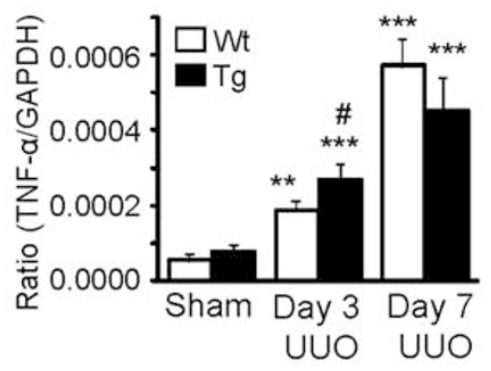

Day 7

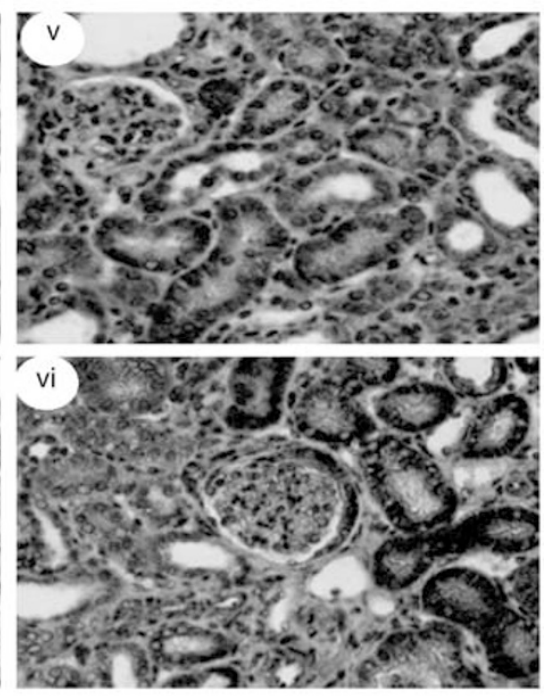

ix TNF-amRNA (D14)

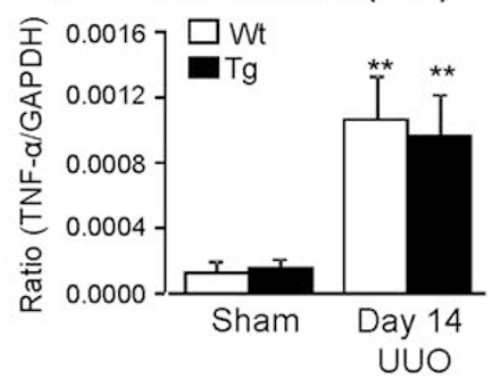

Figure 3 Immunohistochemistry and real-time PCR detect that overexpression of CRP enhances TNF- $\alpha$ and IL-1 $\beta$ expression in the UUO kidney. (a) TNF- $\alpha$. (b) IL-1 $\beta$. (i) A normal kidney from a shamed Wt mouse, (ii) a normal kidney from a shamed CPRtg mouse, (iii) a UUO kidney from a Wt mouse at day 3 after UUO, (iv) a UUO kidney from a CPRtg mouse at day 3 after UUO, (v) a UUO kidney from a Wt mouse at day 7 after UUO, (vi) a UUO kidney from a CPRtg mouse at day 7 after UUO, (vii) quantitative analysis of immunohistochemical staining, (viii) quantitative analysis of mRNA expression by real-time PCR of UUO kidney (days 3-7). Note that the expression of renal TNF- $\alpha$ and IL-1 $\beta$ are significantly promoted in CRPtg mice at day 3 after UUO when compared with Wt UUO mice. (ix) Quantitative analysis of mRNA expression by real-time PCR of UUO kidney (day 14). Sections were

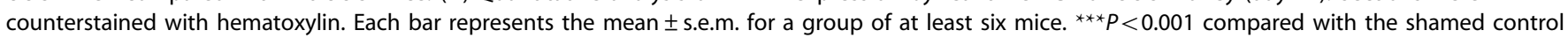
mice. ${ }^{\#} P<0.05,{ }^{\# \#} P<0.01$ as compared with the time-matched Wt mice with UUO. Magnification $\times 200$. 
b
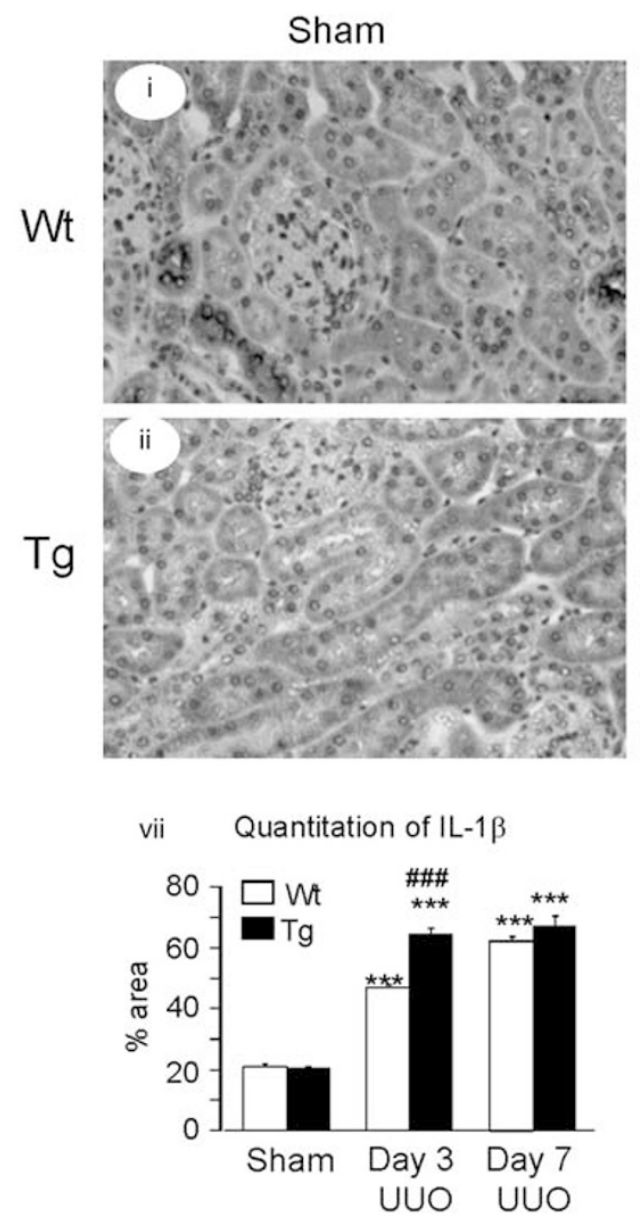

\section{IL-1 $\beta$ expression}
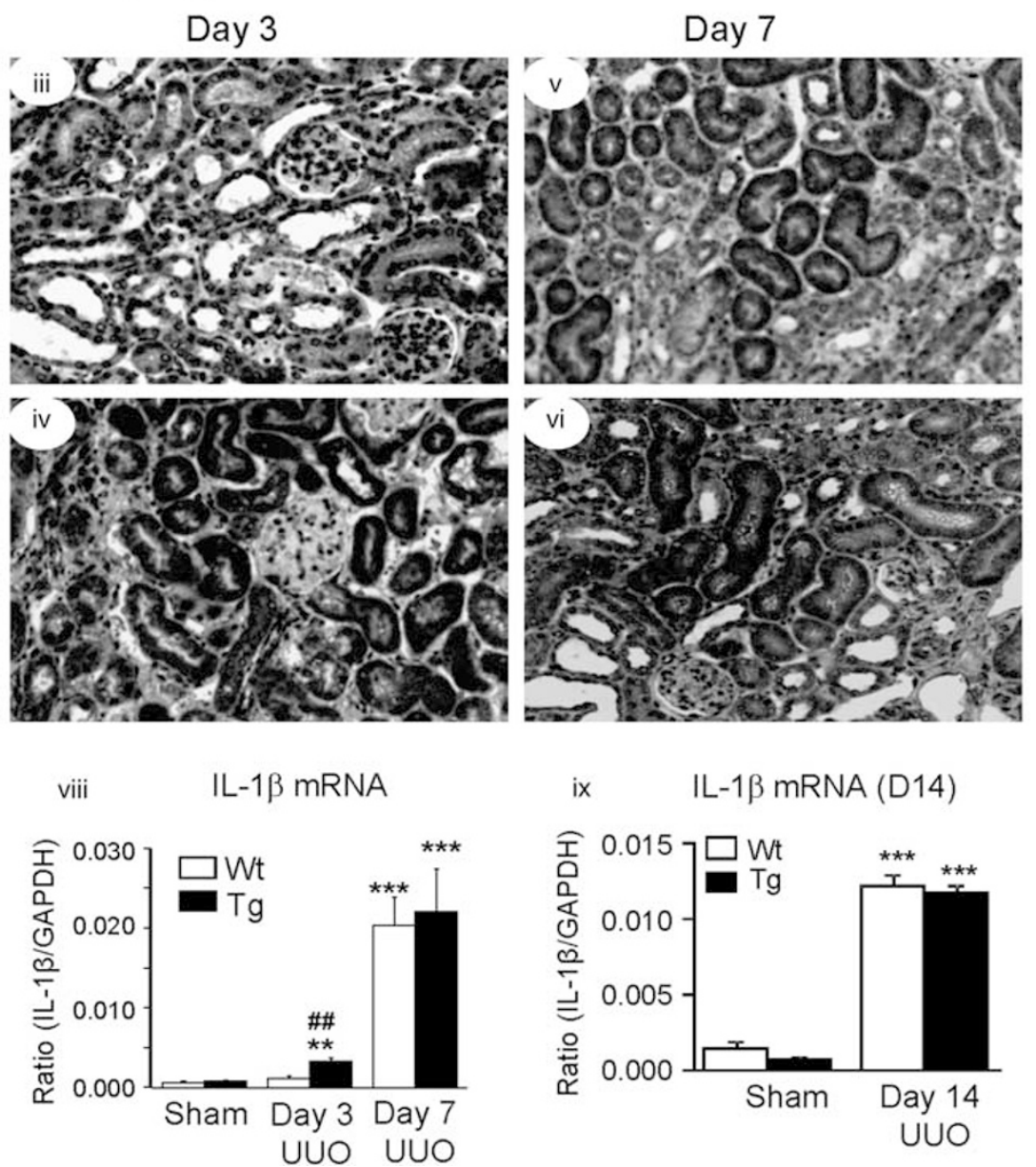

Figure 3 Continued

instructions. Serum human CRP was detected only in CRPtg by human CRP-specific ELISA but was undetectable in $\mathrm{Wt}$ mice. The experimental procedures were approved by the Animal Experimental Ethnic Committee at the Chinese University of Hong Kong.

\section{Real-Time PCR}

Total RNA was isolated using the RNeasy kit, according to the manufacturer's instructions (Qiagen, Valencia, CA, USA). Real-time reverse transcriptase (RT)-PCR was performed as previously described. ${ }^{22-25}$ The primers used in this study for measuring mRNA of inflammatory markers (IL-1 $\beta$, TNF- $\alpha$, MCP-1, ICAM-1), fibrosis markers (TGF- $\beta 1$, collagen I, collagen III, and $\alpha$-smooth muscle actin ( $\alpha$-SMA)), and the housekeeping gene GAPDH were all described previously. ${ }^{22-25}$ The primers used for detecting mouse CRP and Fc $\gamma$ RI were mouse CRP: forward: $5^{\prime}$-ATG GAG AAG CTA CTC TGG TG C-3', reverse: 5'-ACA CAC AGT AAA GGT GTT CAG TG-3'; and mouse Fc $\gamma$ RI: forward: $5^{\prime}$-CAC AAA TGC CCT TAG ACC AC-3', reverse: 5'-ACC CTA GAG TTC CAG GGA TG$3^{\prime}$; Reaction specificity was confirmed by melting curve analysis. The ratio for the mRNA examined was normalized with GAPDH and expressed as the mean \pm standard errors of the mean (s.e.m.).

\section{Histology and Immunohistochemistry}

Change in renal morphology was examined on methyl Carnoy's-fixed, paraffin-embedded tissue sections $(3 \mu \mathrm{m})$ stained with hematoxylin and eosin or periodic acid-Schiff (PAS). Immunostaining was performed on paraffin sections using a microwave-based antigen retrieval technique. ${ }^{26}$ The antibodies used in this study included rabbit antibodies against phospho-NF- $\kappa \mathrm{B} / \mathrm{p} 65$ (Cell Signaling, Danvers, MA, USA), phospho-Smad2/3, IL-1 $\beta$, TNF- $\alpha$, TGF- $\beta 1$, ICAM-1 (Santa Cruz Biotechnology, Santa Cruz, CA, USA), collagen types I and III (Southern Tech, Birmingham, AL, USA), $\alpha$-SMA (Sigma, St Louis, MO, USA), MCP-1 (eBioscience, San Diego, CA, USA), CD3 + T cells (SP7) (Abcam, Cambridge, UK), and a rat anti-mouse monoclonal antibody to macrophages (F4/80) (Serotec, Oxford, UK). In addition, a rabbit polyclonal antibody against human, rat, and mouse CRP (Syd Labs, Malden, MA, USA) was used to identify the 
expressing patterns of CRP in both normal and diseased kidney. An isotype-matched rabbit IgG (Sigma) was used as negative control throughout the study. All slides (except with antibodies against phospho-NF- $\kappa \mathrm{B} / \mathrm{p} 65$, phospho-Smad2/3, and $\alpha$-SMA) were counterstained with hematoxylin.

Quantitation of immunostaining was carried out on coded slides. Expression of IL- $1 \beta$, TNF- $\alpha$, MCP-1, ICAM-1, CRP, and TGF- $\beta$ in the entire cortex (a cross-section of the kidney) was determined using the quantitative Image Analysis System (AxioVision 4, Carl Zeiss, Germany) and data were expressed as percentage of positive area as previously described. ${ }^{22-24}$ The number of F4/80 +, CD3 +, phospho-Smad2/3+, and phospho-NF- $\kappa \mathrm{B} / \mathrm{p} 65+$ cells in the tubulointerstitium was counted in 20 consecutive fields under high-power fields $(\times 40)$ by means of a $0.0625-\mathrm{mm}^{2}$ graticule fitted in the eyepiece of the microscope and expressed as cells per $\mathrm{mm}^{2}$, positive cells within the glomerulus were counted in 20 consecutive glomeruli and expressed as cells/glomerular cross-section.

\section{Statistical Analyses}

The data obtained are expressed as the mean \pm s.e.m. Statistical analyses were performed using one-way ANOVA followed by Newman-Keuls post test (Prism 4.0 GraphPad Software, San Diego, CA, USA).

\section{RESULTS \\ CRPtg Mice Exhibit Early Development of Obstructive Nephropathy}

Human CRP serum levels were $8.0 \pm 0.7 \mathrm{mg} / \mathrm{l}$ at the baseline and marginally increased after UUO $(10.5 \pm 0.5 \mathrm{mg} / \mathrm{l}$ and $11.2 \pm 0.3 \mathrm{mg} / \mathrm{l}$ on day 3 and day 7, respectively).

Kidneys harvested from Wt and CRPtg mice subjected to sham surgery were normal without remarkable changes upon

a MCP-1 expression
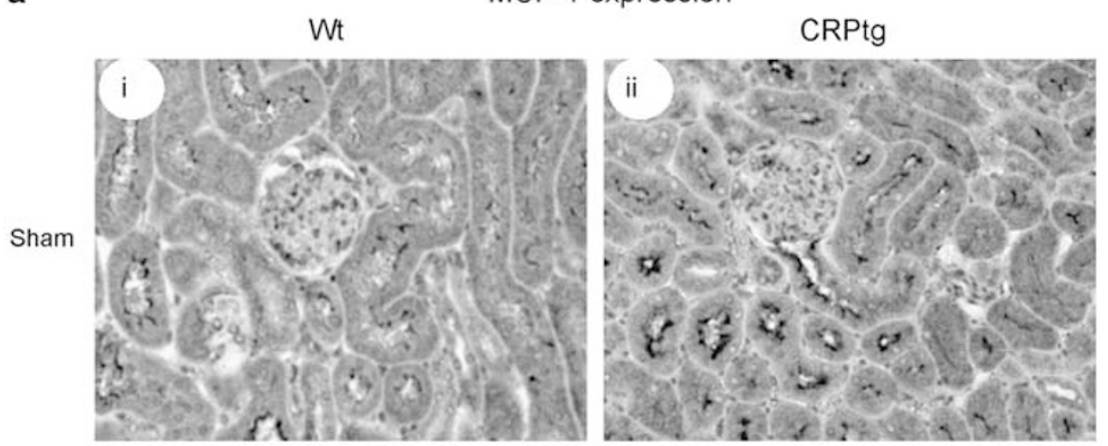

vii

Quantitation of MCP-1
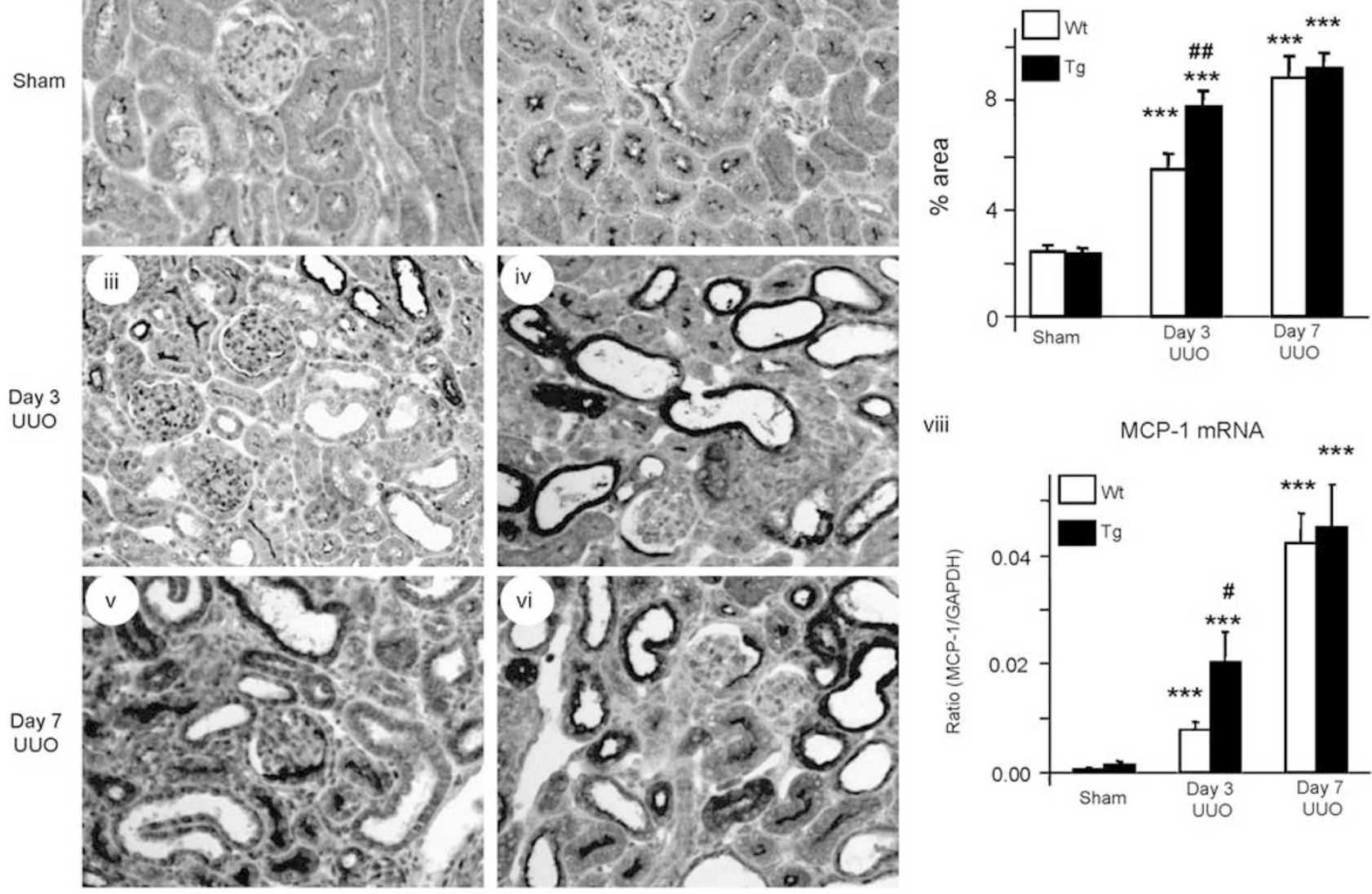

viii

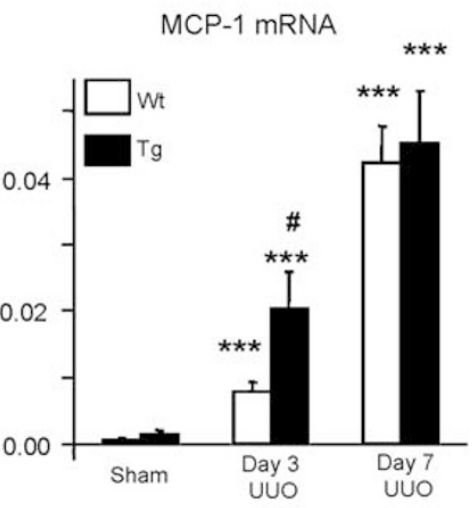

Figure 4 Immunohistochemistry and real-time PCR detect that overexpression of CRP enhances MCP-1 and ICAM-1 expression in the UUO kidney. (a) MCP-1. (b) ICAM-1. (i) A normal kidney from a shamed Wt mouse, (ii) a normal kidney from a shamed CPRtg mouse, (iii) a UUO kidney from a Wt mouse at day 3 after UUO, (iv) a UUO kidney from a CPRtg mouse at day 3 after UUO, (v) a UUO kidney from a Wt mouse at day 7 after UUO, (vi) a UUO kidney from a CPRtg mouse at day 7 after UUO, (vii) quantitative analysis of immunohistochemical staining, (viii) quantitative analysis of mRNA expression by realtime PCR. Note that CRPtg mice significantly promote the expression of renal MCP-1 and ICAM-1 at day 3 after UUO when compared with Wt UUO

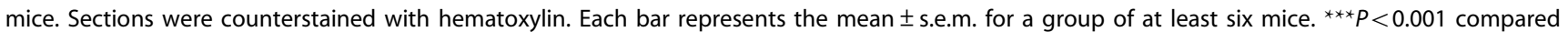
with the shamed control mice. ${ }^{\#} P<0.05,{ }^{\# \# P<0.01}$ as compared with the time-matched Wt mice with UUO. Magnification $\times 200$. 

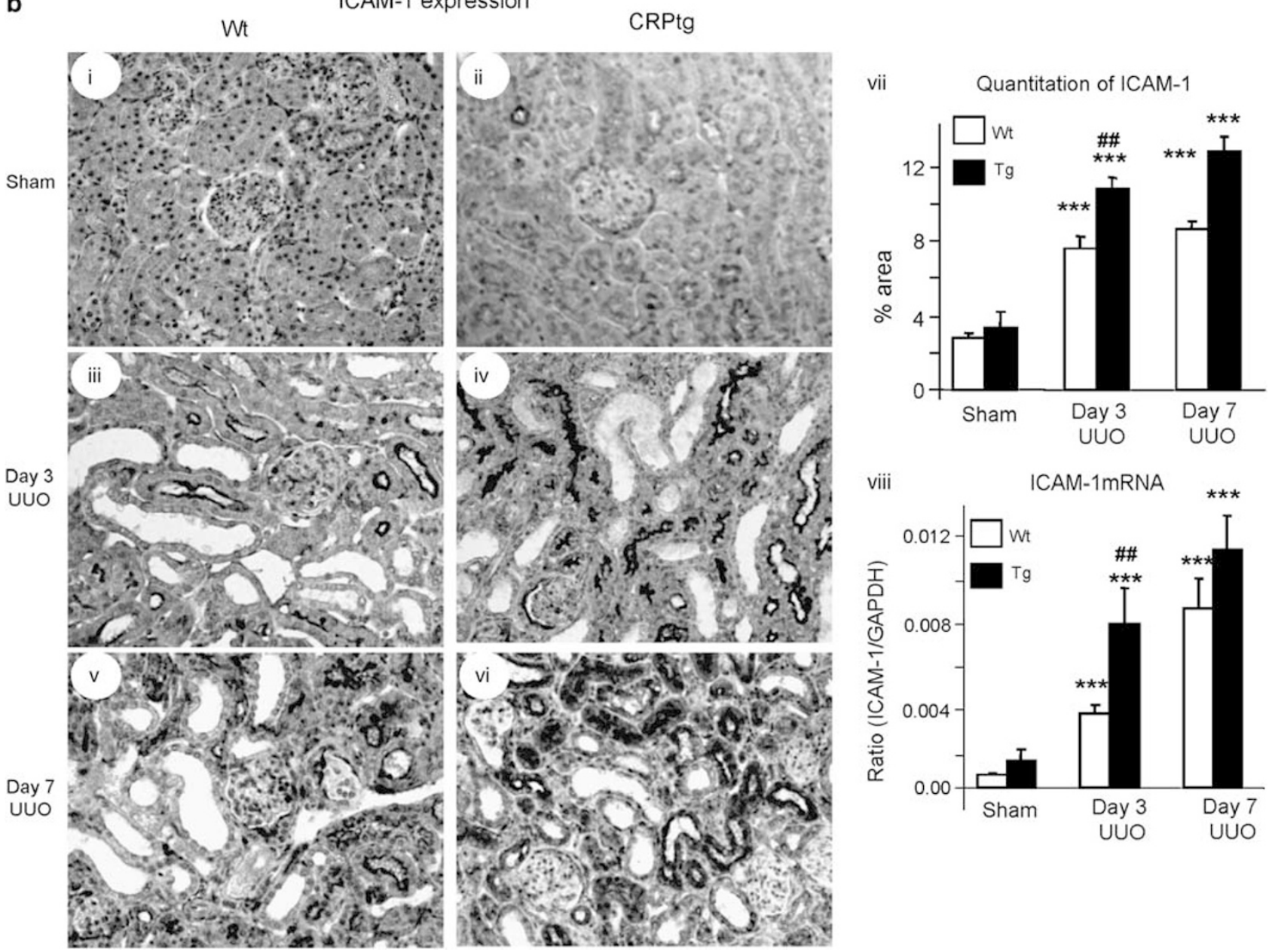

Figure 4 Continued.

histological examination (Figure 1, i and ii). At day 3 after UUO, Wt mice developed moderate tubulointerstitial injury characterized by focal tubular dilation with flattened epithelium, tubular atrophy, expansion of the interstitial space with moderate fibrosis and inflammation (Figure 1, iii). However, CRPtg mice exhibited more severe tubulointerstitial inflammation and fibrosis than that seen in Wt mice at day 3 UUO kidneys (Figure 1, iv). Interestingly, on day 7 and day 14 after UUO, though tubulointerstitial damage was more prominent, an equal degree of tubulointerstitial damage was observed in both $\mathrm{Wt}$ and CRPtg mice (Figure 1, v-viii).

\section{Early Development of Obstructive Nephropathy in CRPtg Mice Is Associated with Enhanced Renal Inflammation and Fibrosis}

By immunohistochemistry, there were a few $\mathrm{F} 4 / 80+$ macrophages and $\mathrm{CD} 3+\mathrm{T}$ cells in sham-operated kidneys from CRPtg and Wt mice (Figure 2ai, aii and bi, bii). By day 3 after UUO, the numbers of $\mathrm{F} 4 / 80+$ macrophages and CD3 + $\mathrm{T}$ cell infiltrating the damaged tubulointerstitium were significantly increased in Wt mice, which was doubled in CRPtg mice (Figure 2aiii, aiv, biii, biv, and c). However, at day 7 and day 14 after UUO, despite further increases in F4/ $80+$ macrophages and CD3 $+\mathrm{T}$ cells in both CRPtg and Wt mice, the numbers of $\mathrm{F} 4 / 80+$ and $\mathrm{CD} 3+$ cells in CRPtg versus Wt kidneys were no longer significantly different (Figure 2av-viii, bv-viii, and c).

We also examined expression of renal proinflammatory cytokines (TNF- $\alpha$ and IL-1 $\beta$ ), chemokines (MCP-1), and adhesion molecules (ICAM-1) by immunohistochemistry and real-time PCR. As shown in Figures 3 and 4, compared with sham-operated kidneys, expression of IL-1 $\beta$, TNF- $\alpha$, MCP-1, and ICAM-1 were significantly upregulated in both CRPtg and Wt mice by day 3 after UUO, but much more remarkable in the UUO kidneys of CRPtg mice (Figures $3 \mathrm{a}$ and bi-iv, bvii, bviii and $4 \mathrm{a}$ and bi-iv, bvii, bviii). Again, by day 7 and day 14 after UUO, expression of these inflammatory cytokines between CRPtg and Wt mice was not significantly different (Figures $3 \mathrm{a}$ and bv-ix and $4 \mathrm{a}$ and bv-viii).

We then determined the fibrotic change in the UUO kidney between CRPtg and Wt mice. Immunohistochemistry 

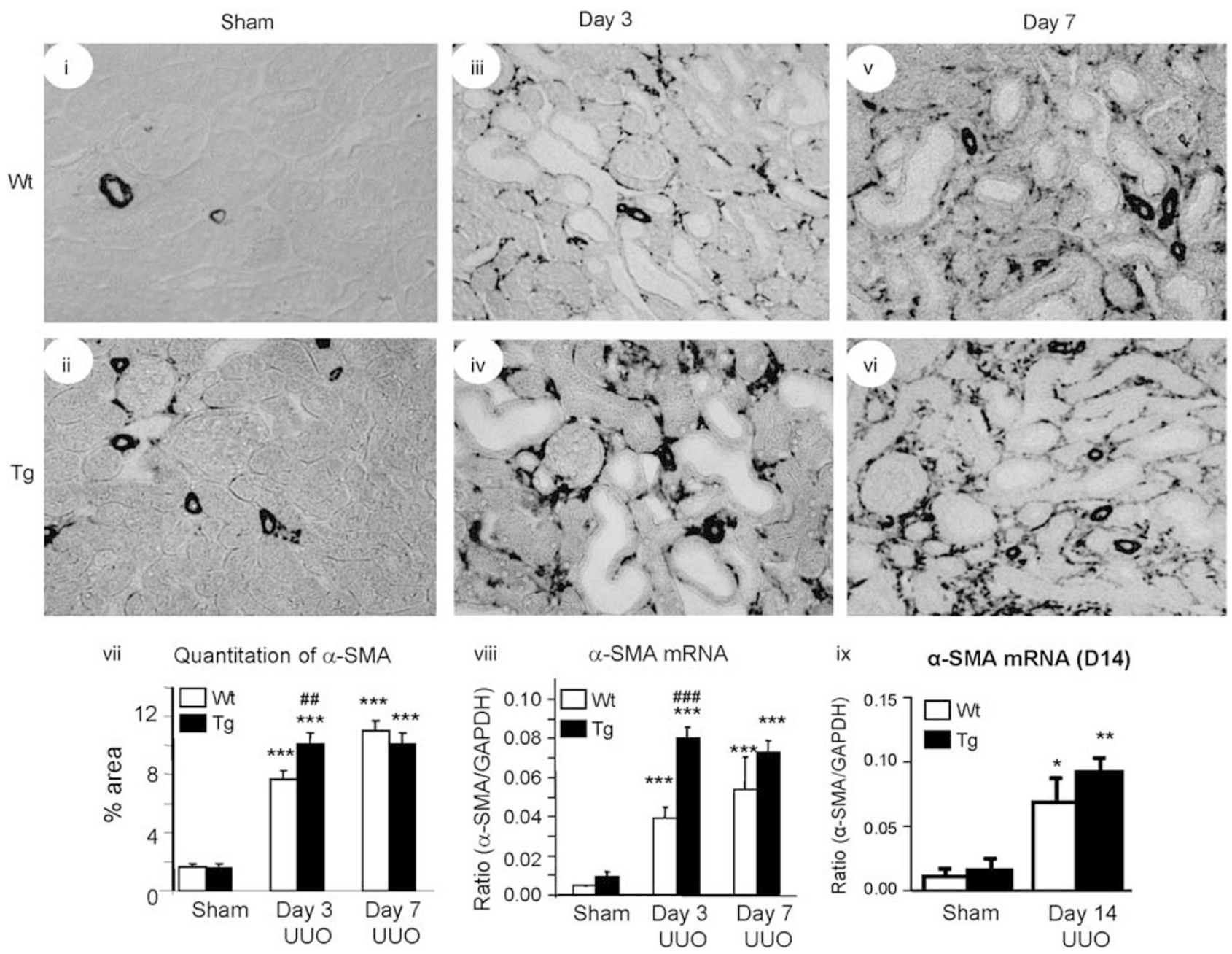

Figure 5 Immunohistochemistry and real-time PCR show that overexpression of CRP enhances $\alpha$-SMA expression in the UUO kidney. (i) A normal kidney from a shamed Wt mouse, (ii) a normal kidney from a shamed CPRtg mouse, (iii) a UUO kidney from a Wt mouse at day 3 after UUO, (iv) a UUO kidney from a CPRtg mouse at day 3 after UUO, (v) a UUO kidney from a Wt mouse at day 7 after UUO, (vi) a UUO kidney from a CPRtg mouse at day 7 after UUO, (vii) quantitative analysis of immunohistochemical staining, (viii) quantitative analysis of mRNA expression by real-time PCR (days 3-7), (ix) quantitative analysis of mRNA expression by real-time PCR (day 14). Note that $\alpha$-SMA + myofibroblast accumulation and mRNA expression are significantly promoted in CRPtg mice at day 3 after UUO when compared with Wt UUO mice. Sections were counterstained with hematoxylin. Each bar represents

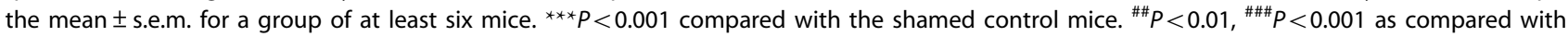
the time-matched Wt mice with UUO. Magnification $\times 200$.

and quantitative real-time PCR revealed that both Wt and CRPtg mice with sham operation demonstrated a normal $\alpha$-SMA level (Figure 5, i, ii, vii-ix). By day 3 after UUO, Wt mice had moderate renal tubulointerstitial fibrosis with moderate $\alpha$-SMA + cell accumulation, whereas CRPtg mice developed more intense $\alpha$-SMA + myofibroblast accumulation with higher mRNA expression (Figure 5, iii-viii). However, by day 7 and day 14 after UUO, although an increase in $\alpha$-SMA + myofibroblast accumulation and upregulation of $\alpha$-SMA mRNA remained prominent in the UUO kidney, no significant difference between CRPtg and Wt mice was noted (Figure 5, v-ix). Likewise, immunohistochemistry and real-time PCR also demonstrated that while low-to-moderate tubulointerstitial fibrosis such as collagen I and III mRNA expression and protein accumula- tion developed in kidneys from Wt mice at day 3 after UUO, which were greatly increased in the UUO kidneys of CRPtg mice (Figure 6a and bi-iv, bvii, bviii). Similar to $\alpha$-SMA expression, collagen I and III mRNA and protein expression in the UUO kidney of Wt and CRPtg mice reached comparable levels by day 7 and day 14 (Figure 6a and bv-ix).

\section{Early Development of Renal Fibrosis and Inflammation after UUO Is Associated with Enhanced Endogenous Mouse CRP and FcyRI Expression and Activation of the TGF- $\beta /$ Smad2/3 and NF- $\kappa$ B/P65 Signaling Pathways in CRPtg Mice}

Because CRP mediates neointimal thickening and proinflammatory cytokine production via the Fc $\gamma$ RI-dependent mechanism, ${ }^{27,28}$ and activation of the TGF- $\beta /$ Smad $2 / 3$ and 
$\mathrm{NF}-\kappa \mathrm{B} / \mathrm{p} 65$ signaling pathways has a critical role in renal fibrosis and inflammation, ${ }^{29-34}$ we investigated whether the enhancement of renal inflammation and fibrosis in human CRPtg mice was associated with increased expression endogenous mouse CRP and Fc $\gamma$ RI and activation of TGF- $\beta /$ Smad and NF- $\kappa \mathrm{B}$ signaling. As shown by real-time PCR, we found that a significant increase in mouse CRP and its $\mathrm{Fc} \gamma \mathrm{RI}$ expression was found in the UUO kidney of human CRPtg mice, but not in Wt mice at day 3 after UUO (Figure 7a). Interestingly, upregulation of mouse CRP and Fc $\gamma \mathrm{RI}$ reached comparable levels in both CRPtg and Wt mice by day 7 and day 14 (Figure 7a). By immunohistochemistry, we also found that normal CRPtg mice readily expressed a high level of CRP by all kidney cell types, particularly by tubular epithelial cells and this was maintained in UUO CRP mice over the entire disease course (Figure $7 \mathrm{~b}$ ). In contrast, Wt mice expressed trace CRP in the normal kidney, but significantly increased in UUO nephropathy at day 3 , reaching to comparable levels to the CRPtg mice from day 7 onwards (Figure $7 b$ ).

We next examined NF- $\kappa \mathrm{B}$ and TGF- $\beta /$ Smad signaling during the progression of UUO kidney. As shown in Figure 8, immunohistochemistry revealed that compared with readily activated NF- $\kappa \mathrm{B} / \mathrm{p} 65$ in Wt mice, CRPtg mice exhibited a more remarkable activation of NF- $\kappa \mathrm{B} / \mathrm{p} 65$ in the damaged tubulointerstitium at day 3 , but reached to comparable levels with Wt mice over days 7-14 after UUO (as demonstrated by the increased nuclear localization of phosphorylated NF- $\kappa \mathrm{B} /$ p65 in renal tissues). Similarly, both real-time PCR and western blot analyses showed that while Wt mice had significant high levels of TGF- $\beta 1$ expression and Smad2/3 activation from day 3 onwards, CRPtg mice had much higher levels of TGF- $\beta 1$ and activation of Smad2/3 signaling at a
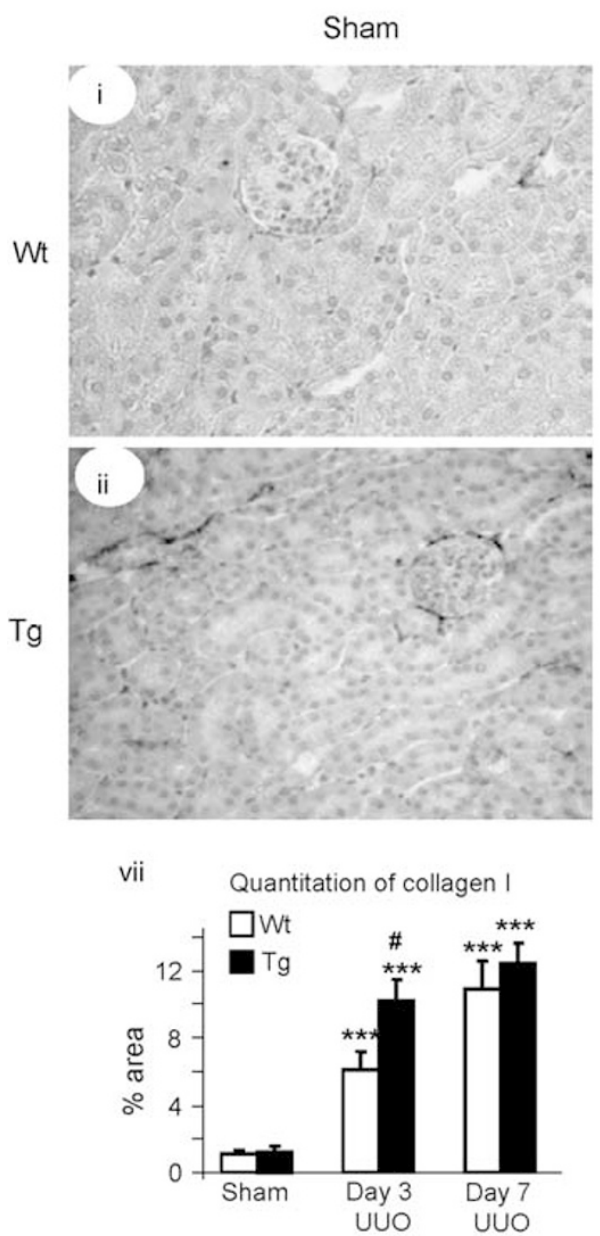

Collagen I expression

Day 3
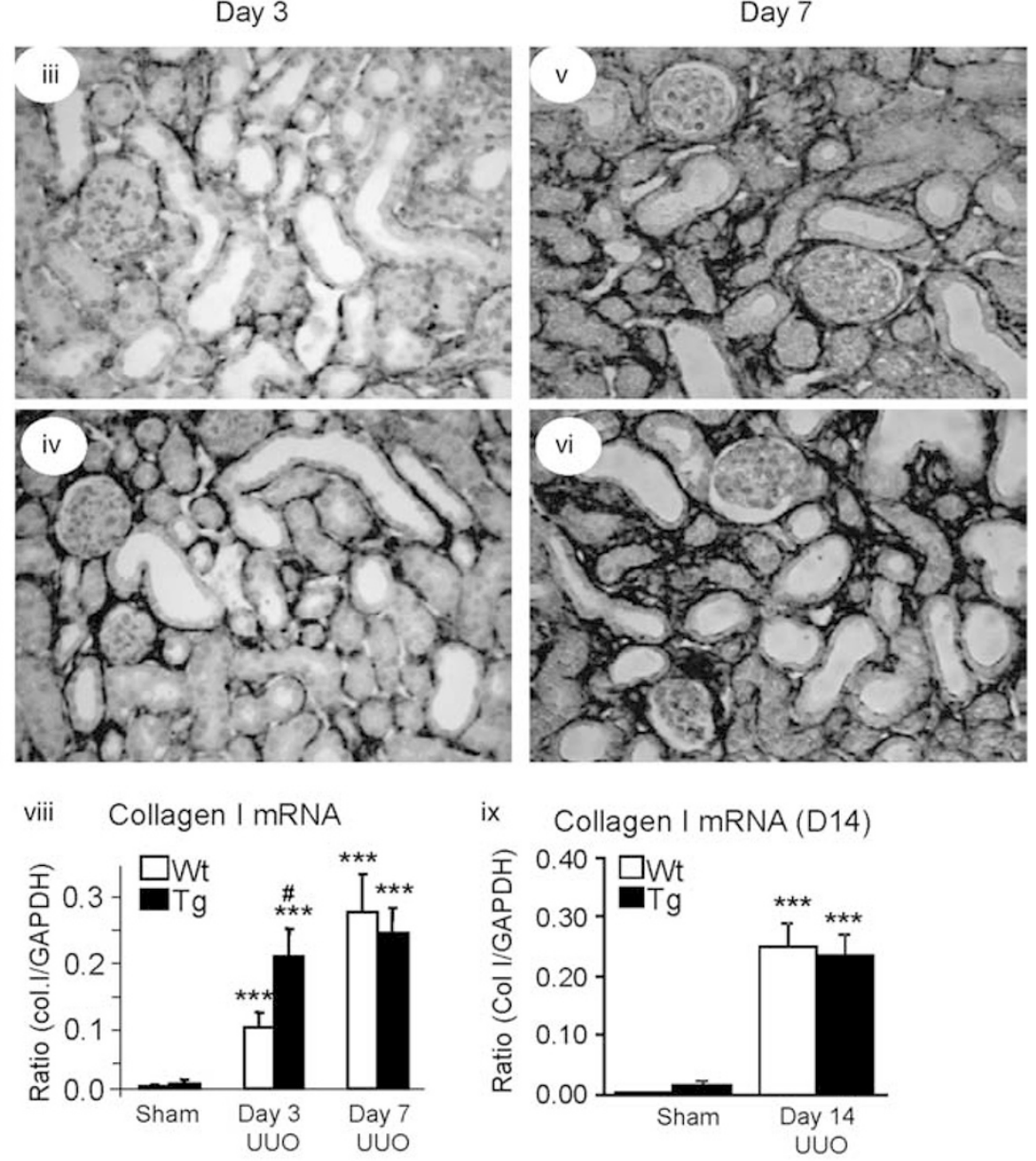

ix Collagen I mRNA (D14)

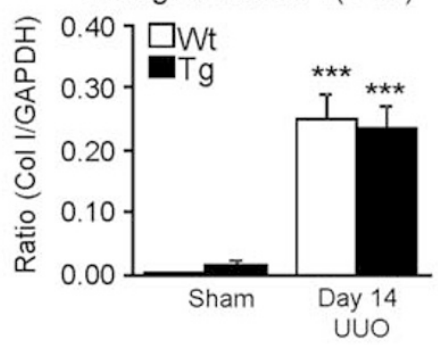

Figure 6 Immunohistochemistry and real-time PCR detect that overexpression of CRP enhances collagen I and III expression in the UUO kidney. (a) Collagen I. (b) Collagen III. (i) A normal kidney from a shamed Wt mouse, (ii) a normal kidney from a shamed CPRtg mouse, (iii) a UUO kidney from a Wt mouse at day 3 after UUO, (iv) a UUO kidney from a CPRtg mouse at day 3 after UUO, (v) a UUO kidney from a Wt mouse at day 7 after UUO, (vi) a UUO kidney from a CPRtg mouse at day 7 after UUO, (vii) quantitative analysis of immunohistochemical staining, (viii) quantitative analysis of

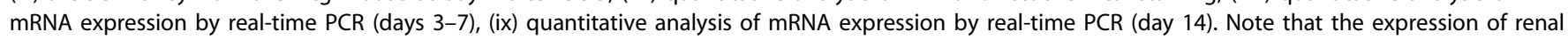
collagen I and III are significantly promoted in CRPtg mice at day 3 after UUO when compared with Wt UUO mice. Sections were counterstained with hematoxylin. Each bar represents the mean \pm s.e.m. for a group of at least six mice. ${ }^{\star * *} P<0.001$ compared with the shamed control mice. ${ }^{\sharp} P<0.05$, ${ }^{\# \#} P<0.01$ as compared with the time-matched Wt mice with UUO. Magnification $\times 200$. 
b
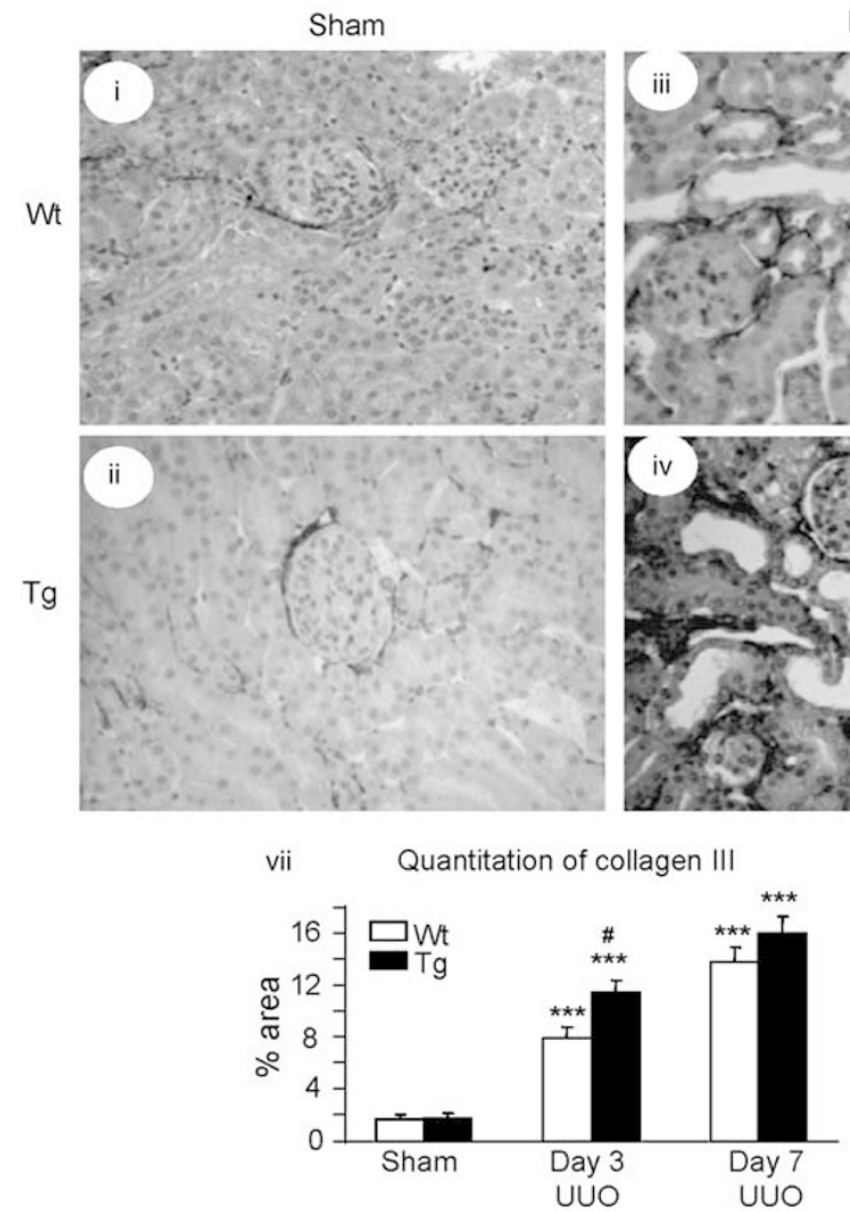

Collagen III expression
Day 3
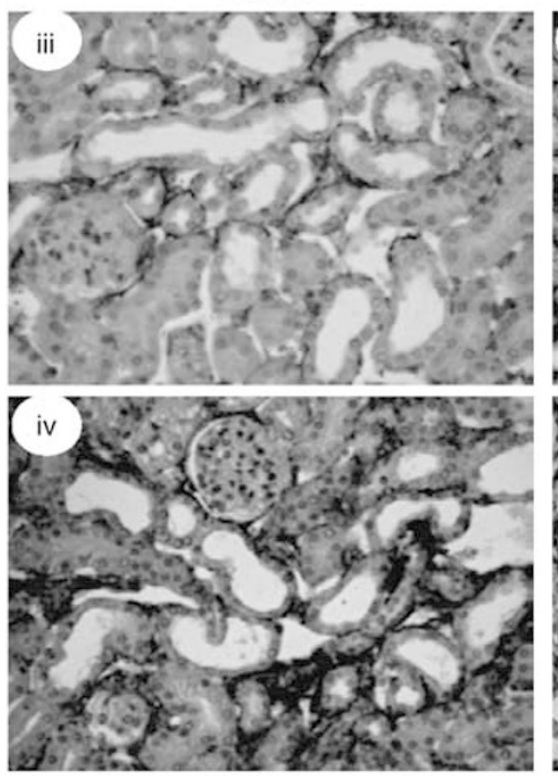

Day 7
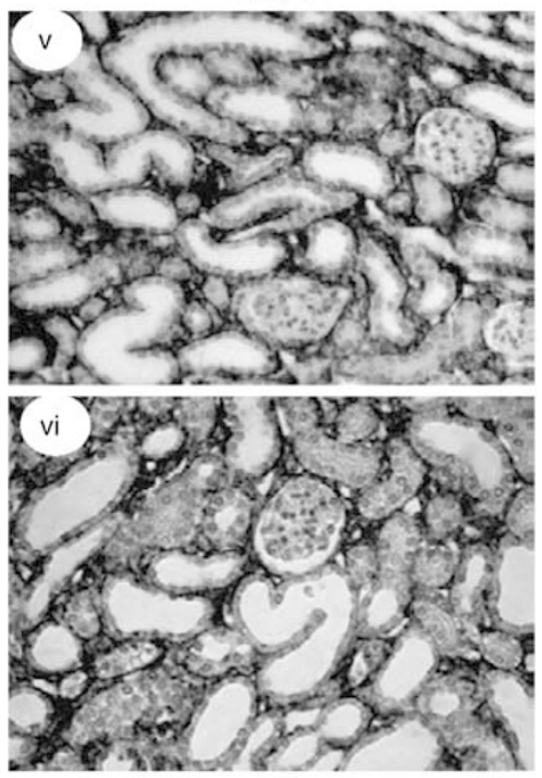

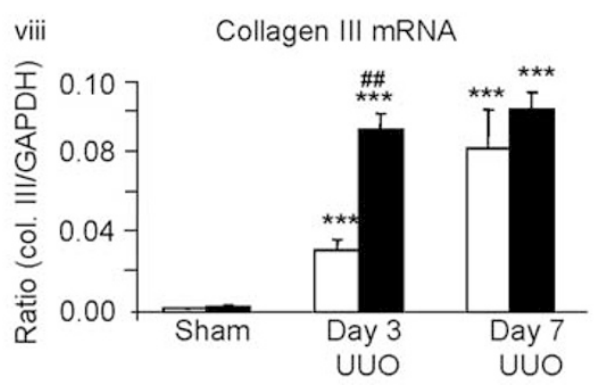

Figure 6 Continued.

day 3, but not at days 7 and 14 when compared with the $\mathrm{Wt}$ mice (Figure 9).

\section{DISCUSSION}

Emerging evidence shows that serum levels of CRP are increased in diseases associated with inflammation, including CKD and ESRD ${ }^{7,8,11,17-19}$. In the present study, we provide strong evidence to support the importance of CRP as a mediator in renal inflammation and fibrosis in CRPtg mice subjected to UUO. We found that mice with higher levels of human CRP developed more rapidly renal inflammation including more severe inflammatory cell infiltration and higher expression of proinflammatory cytokines (IL-1 $\beta$ and TNF- $\alpha$ ), chemokines (MCP-1), and adhesion molecule (ICAM-1), which was associated with enhanced expression of endogenous renal CRP and $\mathrm{F} c \gamma \mathrm{RI}$ and NF- $\kappa \mathrm{B}$ signaling. In addition, increased human CRP also promoted renal fibrosis including $\alpha$-SMA + myofibroblast accumulation and collagen I and III expression and deposition, which is also likely as the result of enhanced TGF- $\beta / \mathrm{Smad}$ signaling. These findings are consistent with our recent finding that transgenic expression of human CRP in CRPtg mice exacerbates angiotensin II-induced cardiac fibrosis and inflammation. ${ }^{15}$

Enhancement of acute renal inflammation appears to be the main deleterious influence of human CRP in obstructive nephropathy in the CRPtg mouse. Consistent with previous findings that $\mathrm{CRP}$ is able to induce expression of inflammatory proteins (TNF- $\alpha$, IL- $1 \beta$, MCP- 1 , and ICAM- 1 ) in cultured monocytes and endothelial cells, ${ }^{13,14,35,36}$ we provided evidence that increased human CRP levels promote renal expression of these inflammatory genes as well as macrophage and T-cell infiltration in injured CRPtg kidneys as early as day 3 after UUO. In contrast, the progression of renal inflammation in Wt mice was relatively slow, ultimately achieving the same levels of day 3 CRPtg by day 7 . Thus, the findings from this animal study indicate that CRP may act as an early inflammatory mediator to promote renal inflammation.

Enhanced NF- $\kappa \mathrm{B}$ signaling may be the signaling mechanism by which CRP promotes renal inflammation in the UUO kidney. It has been shown that CRP is capable of activating $\mathrm{NF}-\kappa \mathrm{B}$ to induce IL- $1 \beta$ and TNF- $\alpha$ expression in vitro. ${ }^{29,31,36}$ 
a

i

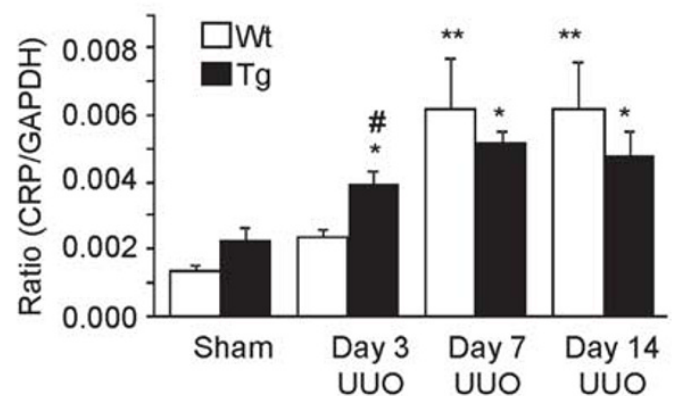

Expression of mouse CRP and FcyRI mRNA

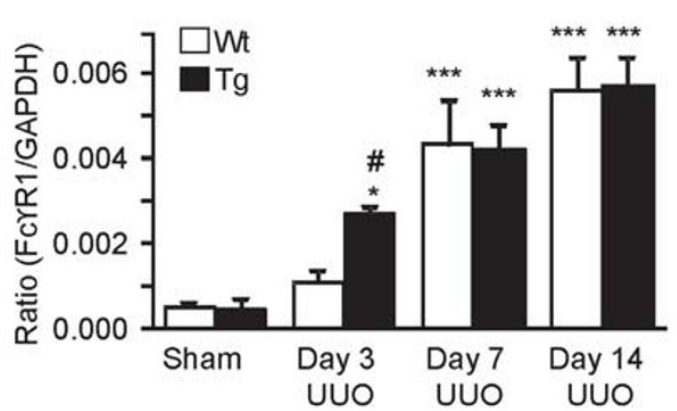

b Sham
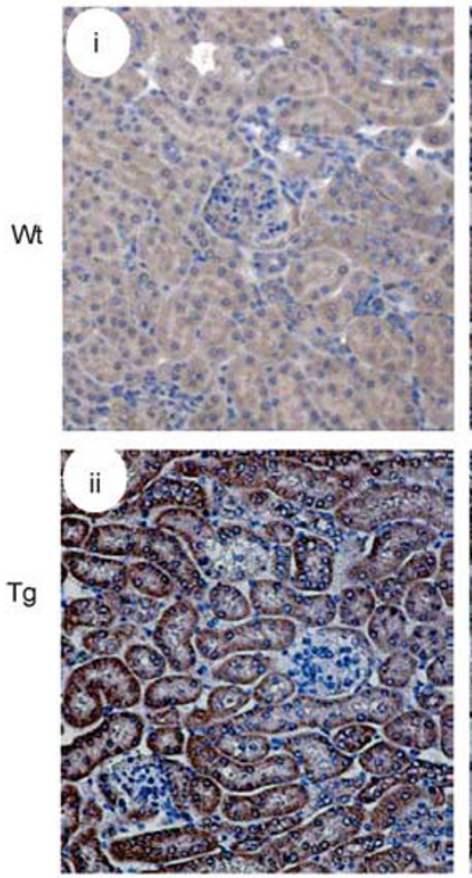

Patterns of CRP expression by immunohistochemistry

Day 3

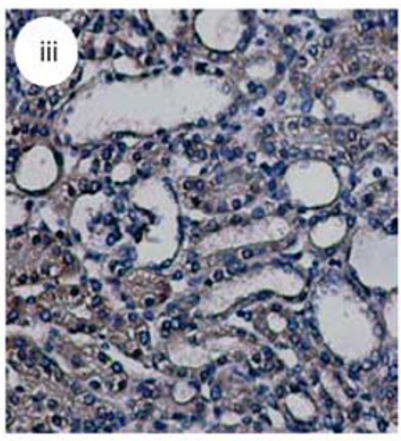

Day 7
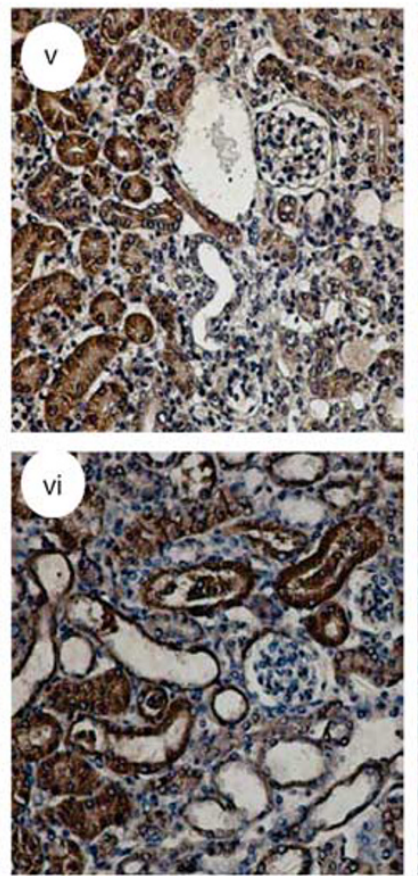

Day 14
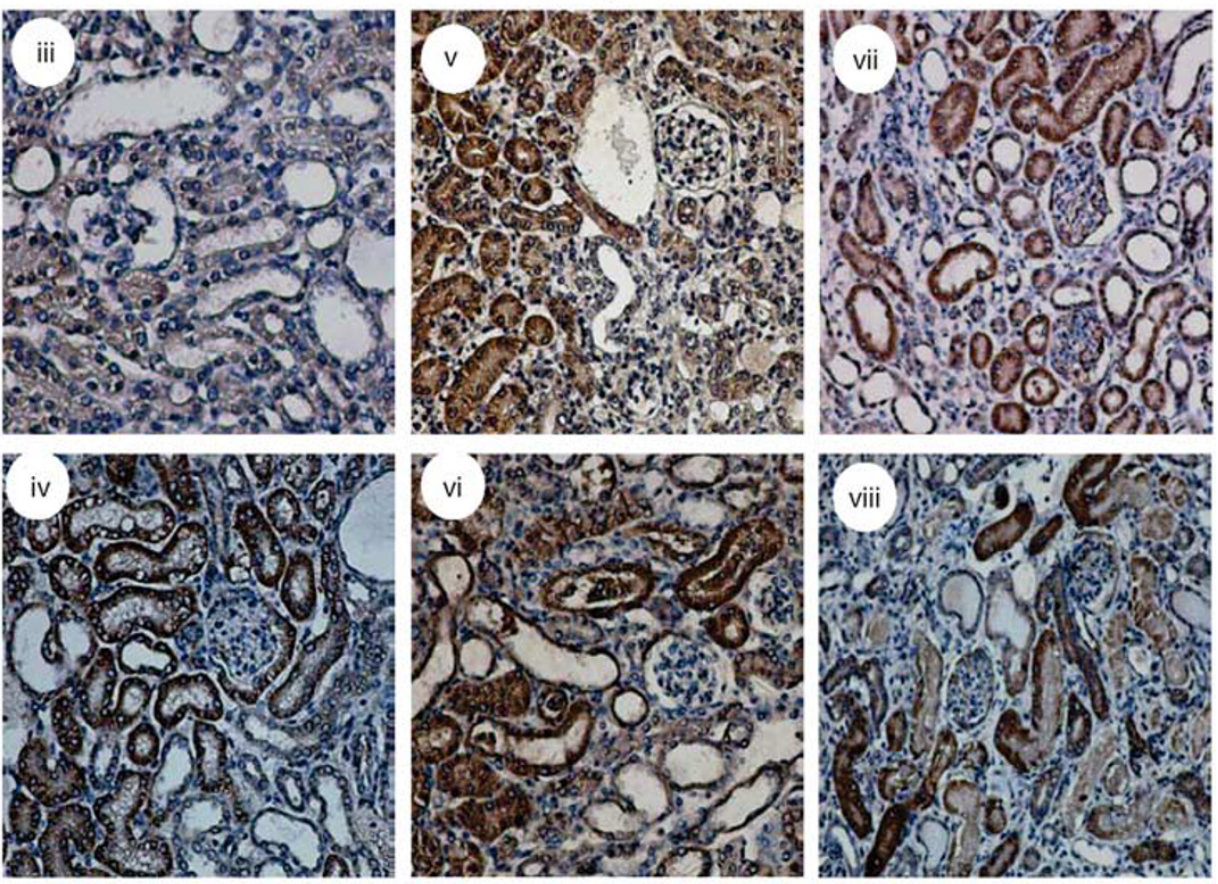

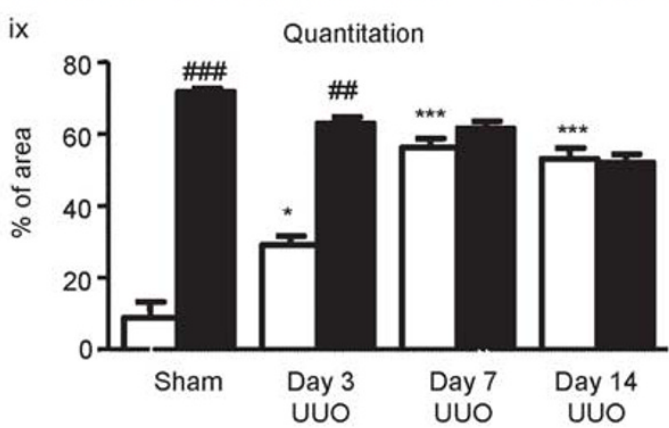

Figure 7 Immunohistochemistry and real-time PCR detect that overexpression of human CRP significantly enhances renal CRP and Fc $\gamma \mathrm{Rl}$ expression in the acute phase of the UUO kidney. (a) mRNA expression of endogenous mouse renal CRP and F $\gamma \mathrm{RI}$. Note that compared with the Wt mice, more severe renal injury in CRPtg mice is associated with much higher levels of mouse CRP and Fc $\gamma R$ I mRNA at day 3 after UUO. (b) CRP immunohistochemistry detects that normal human CRPtg mice have ready developed a maximal level of CRP expression by all intrinsic kidney cells, particularly by tubular epithelial cells (b, i, ii) and this is maintained throughout the 14-day periods of UUO (b, iv, vi, viii). In contrast, normal Wt mice exhibit a trace CRP expression, which is significantly increased to a moderate level at day 3 and reaches to the comparable levels of CRPtg mice from days 7 onwards (b, iii-ix). Note that a significant difference of CRP expression between CRPtg and Wt mice is noticed at day 3, but not days 7 and 14 after UUO. Each bar represents the mean \pm s.e.m. for a group of at least six mice. ${ }^{*} P<0.05,{ }^{* * P}<0.01$, ${ }_{* * *} P<0.001$ compared with the shamed control mice. ${ }^{\# \#} P<0.01,{ }^{\# \# \#} P<0.001$ as compared with the time-matched Wt mice. Magnification $\times 200$. 

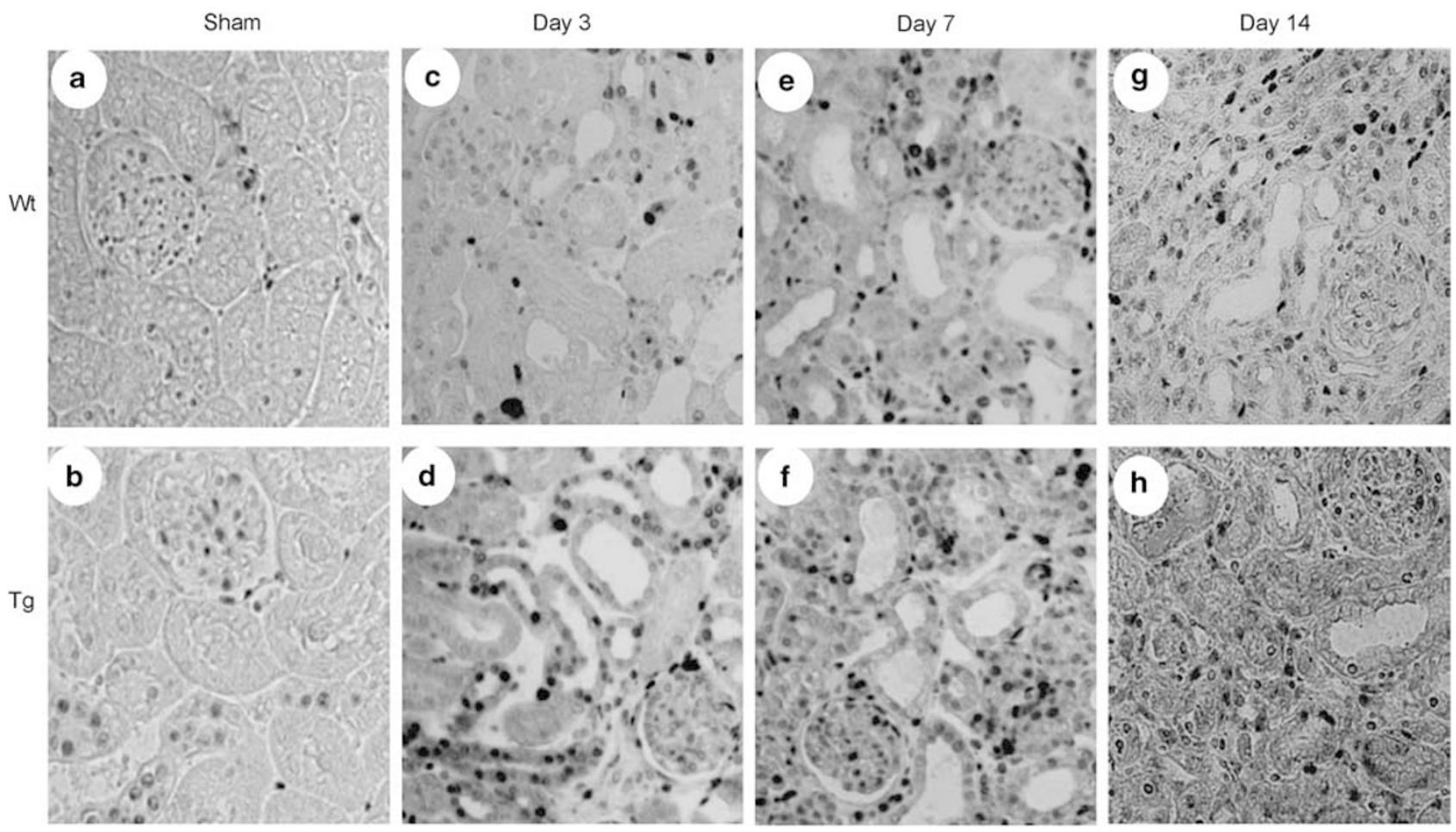

i Quantitation (Glomerulus)

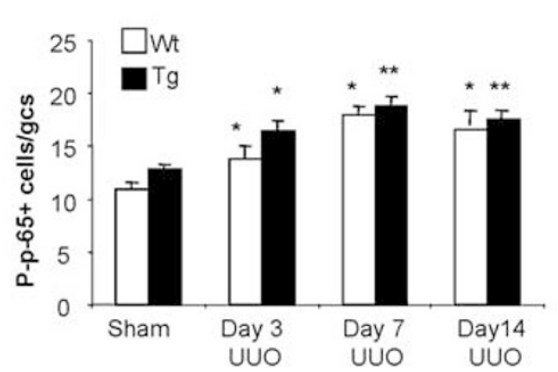

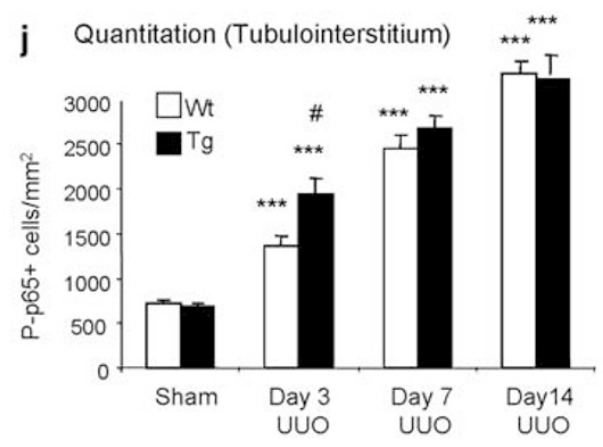

Figure $8 \mathrm{Immunohistochemistry} \mathrm{detects} \mathrm{that} \mathrm{overexpression} \mathrm{of} \mathrm{human} \mathrm{CRP} \mathrm{enhances} \mathrm{NF-} \kappa \mathrm{B} / \mathrm{p} 65$ signaling in the acute UUO kidney at day 3 .

(a) A normal kidney from a shamed Wt mouse, (b) a normal kidney from a shamed CPRtg mouse, (c) a UUO kidney from a Wt mouse at day 3 after UUO, (d) a UUO kidney from a CPRtg mouse at day 3 after UUO, (e) a UUO kidney from a Wt mouse at day 7 after UUO, (f) a UUO kidney from a CPRtg mouse at day 7 after UUO, (g) a UUO kidney from a Wt mouse at day 14 after UUO, (h) a UUO kidney from a CPRtg mouse at day 14 after UUO, (i) quantitative analysis of phospho-p65 in glomeruli, (j) quantitative analysis of phospho-p65 in tubulointerstitium. Note that phospho-p65 nuclear translocation presumably in the damaged tubulointerstitium is significantly increased in CRPtg mice at day 3 after UUO. Each bar represents the mean \pm s.e.m. for a group of at least six mice. ${ }^{\star} P<0.05$, ${ }^{* *} P<0.01$, ${ }^{* *} P<0.001$ compared with the shamed control mice. ${ }^{\#} P<0.05$ as compared with the time-matched Wt mice with UUO. Magnification $\times 400$.

In the present study, we also found that compared with the Wt mice where a maximal activation of NF- $\kappa \mathrm{B}$ signaling was reached by day 7 after UUO, the higher level of CRP in CRPtg mice enhanced activation of NF- $\kappa \mathrm{B}$ signaling and progressive renal inflammation as early as day 3 after UUO. This finding is consistent with a recent study that CRP enhances NF- $\kappa \mathrm{B}$ signaling in angiotensin II-induced cardiac inflammation. ${ }^{15}$

Similarly, enhanced TGF- $\beta /$ Smad signaling may be the key mechanism by which overexpression of CRP accelerated renal fibrosis in the UUO kidney. It is well documented that TGF- $\beta$ signals through its downstream Smad signaling pathway to mediate renal fibrosis. ${ }^{30,32,33,37,38}$ Deletion of Smad3 gene or blockade of Smad2/3 activation by overexpressing Smad7 suppresses renal fibrosis in rodent models of obstructive and remnant kidney disease. ${ }^{34,39-42}$ In addition, TGF- $\beta 1$ is able to regulate CRP expression because CRP response is suppressed in Smad3 knockout mice. ${ }^{41-44}$ Our recent study demonstrated that higher levels of human CRP in CRPtg mice further enhanced angiotensin II-induced cardiac TGF- $\beta 1$ expression and activation of Smad2/3. ${ }^{15}$ Consistently, this study showed that, at day 3 after UUO, high levels of CRP strongly promoted TGF- $\beta /$ Smad signaling by elevating renal TGF- $\beta 1$ expression and activation of Smad $2 / 3$ to reach the comparable levels as observed at day 7 of Wt mice after UUO. 
This rapid and strong activation of TGF- $\beta /$ Smad signaling in CRPtg may contribute to a rapid and progressive renal fibrosis at day 3 of UUO kidney.

An interesting observation from the present study was that human CRP promoted the early development but not the advanced progression of renal inflammation and fibrosis in CRPtg mice. In contrast to normal Wt mice where renal CRP expression was minimal, normal CRPtg mice had ready expressed higher levels of human CRP protein by all intrinsic kidney cells, particularly by tubular epithelial cells. It is possible that the rapid release of constitutive CRP immediately after UUO may attribute to promote the early renal injury. The findings of enhanced renal CRP, Fc $\gamma$ RI, NF- $\kappa$ B, and TGF- $\beta /$ Smad signaling pathways in CRPtg mice on day 3 after UUO may support the notion that CRP acts via its positive amplification loop to promote the acute renal injury. This observation is consistent with the previous findings that CPR acts through its $\mathrm{F}_{\mathrm{c}} \gamma \mathrm{Rs}$, particularly $\mathrm{F} \gamma \gamma \mathrm{RI}$, to enhance neointimal thickness in vivo and production of inflammatory cytokines in vitro. ${ }^{27,28}$ However, once the renal inflammation and fibrosis are well developed, other proinflammatory cytokines and mediators may likely override the CRP to determine the progression of renal outcomes. Thus, no differences in renal inflammation and fibrosis were detected between CRPtg and Wt mice on day 7 and day 14 of UUO kidneys. These observations may explain the controversial clinical findings a
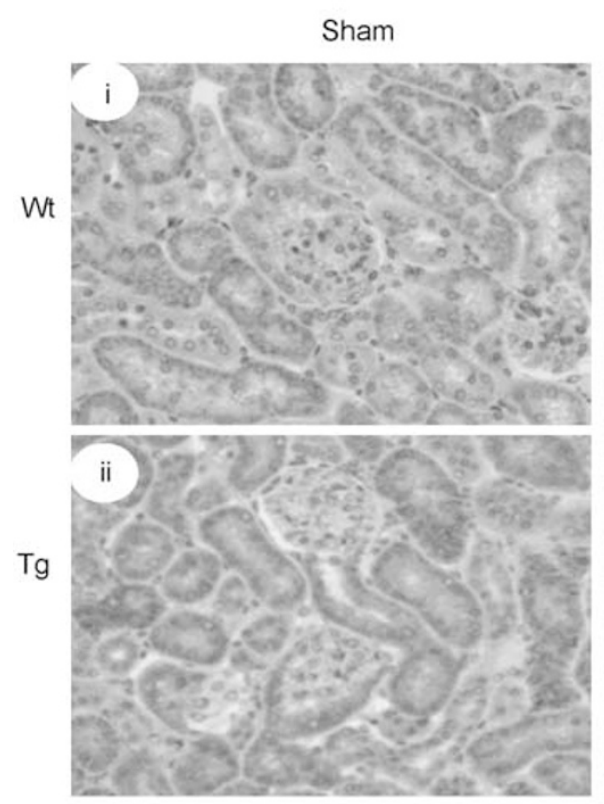

vii

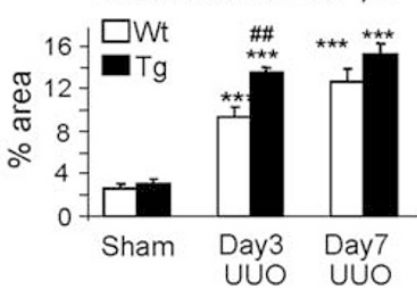

TGF- $\beta 1$ expression

Day 3
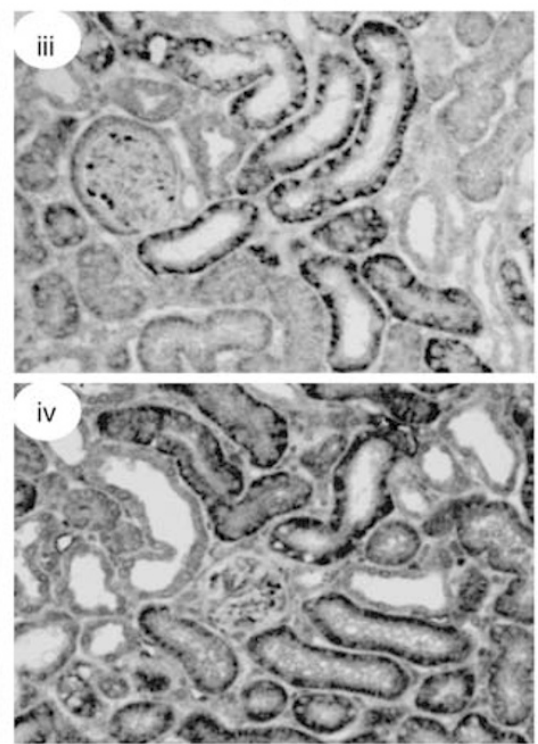

Day 7
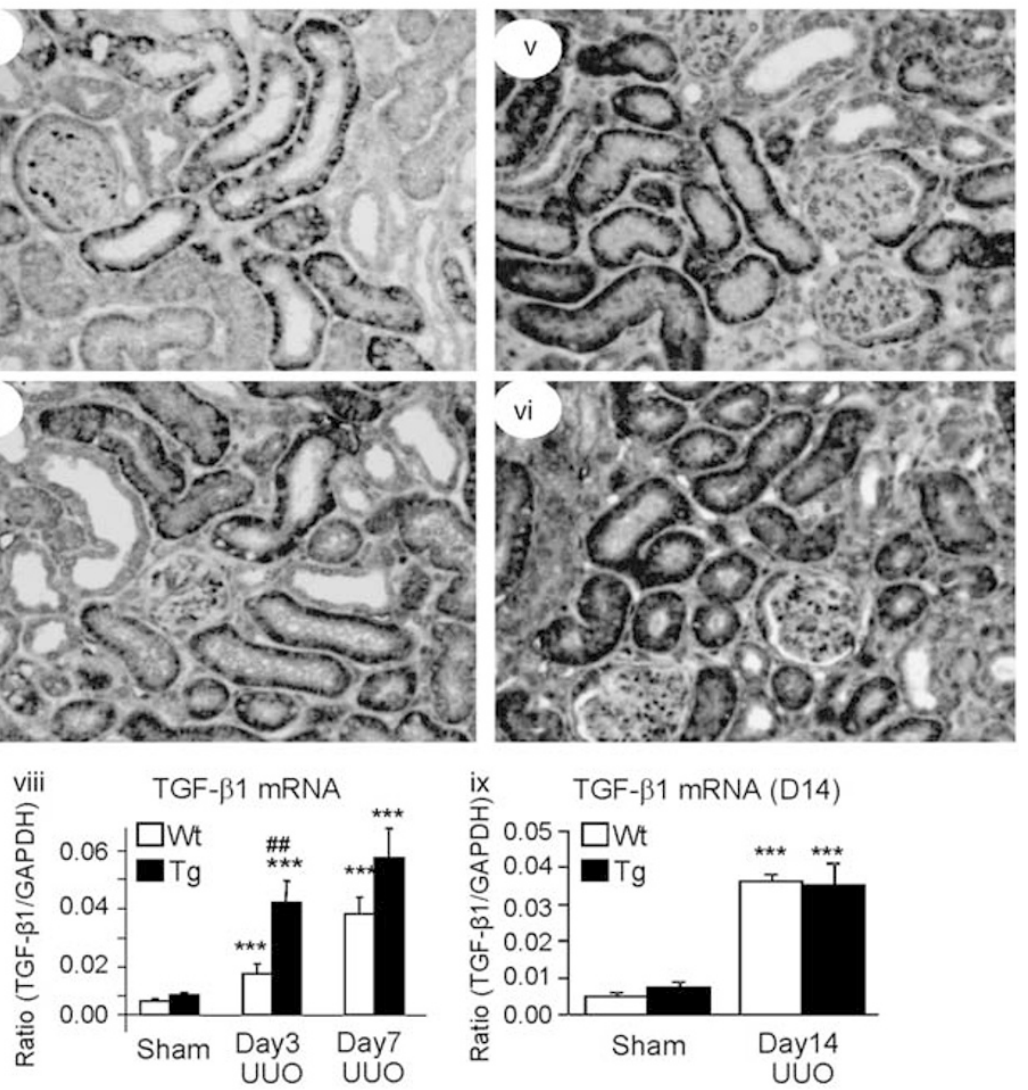

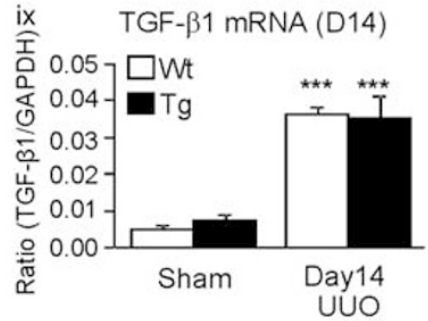

Figure 9 Immunohistochemistry and real-time PCR detect that overexpression of human CRP enhances TGF- $\beta 1$ expression and activation of Smad2/3 in the UUO kidney. (a) TGF- $\beta 1$. (b) Phospho-Smad2/3. (i) A normal kidney from a shamed Wt mouse, (ii) a normal kidney from a shamed CPRtg mouse, (iii) a UUO kidney from a Wt mouse at day 3 after UUO, (iv) a UUO kidney from a CPRtg mouse at day 3 after UUO, (v) a UUO kidney from a Wt mouse at day 7 after UUO, (vi) a UUO kidney from a CPRtg mouse at day 7 after UUO, (vii) quantitative analysis of immunohistochemical staining of renal TGF- $\beta 1$ expression (a) or phospho-Smad2/3 in a UUO kidney from a Wt mouse at day 14 after UUO (b), (viii) quantitative analysis of TGF- $\beta 1 \mathrm{mRNA}$ expression in the UUO kidney of days 3-7 by real-time PCR (a) or phospho-Smad2/3 in a UUO kidney from a CRPTg mouse at day 14 after UUO (B), (ix) quantitative analysis of TGF- $\beta$ mRNA expression in the UUO kidney at day 14 by real-time PCR (a) or phospho-Smad2/3 nuclear location in glomerli by immunohistochemistry (b), (x) quantitative analysis of phospho-Smad2/3 nuclear location in the tubulointerstitium (b). Note that the expression of renal TGF- $\beta 1$ and activation of TGF- $\beta$ signaling in damaged tubulointerstitum are significantly promoted in CRPtg mice as demonstrated by phospho-Smad2/3 nuclear location at day 3 after UUO when compared with Wt UUO mice. Sections were counterstained with hematoxylin. Each bar represents the mean \pm s.e.m. for a group of at least six mice. ${ }^{*} P<0.05,{ }^{* *} P<0.001$ compared with the shamed control mice. ${ }^{\#} P<0.05,{ }^{\# \#} P<0.01$ as compared with the time-matched Wt mice with UUO. Magnification $\times 200$. 
b
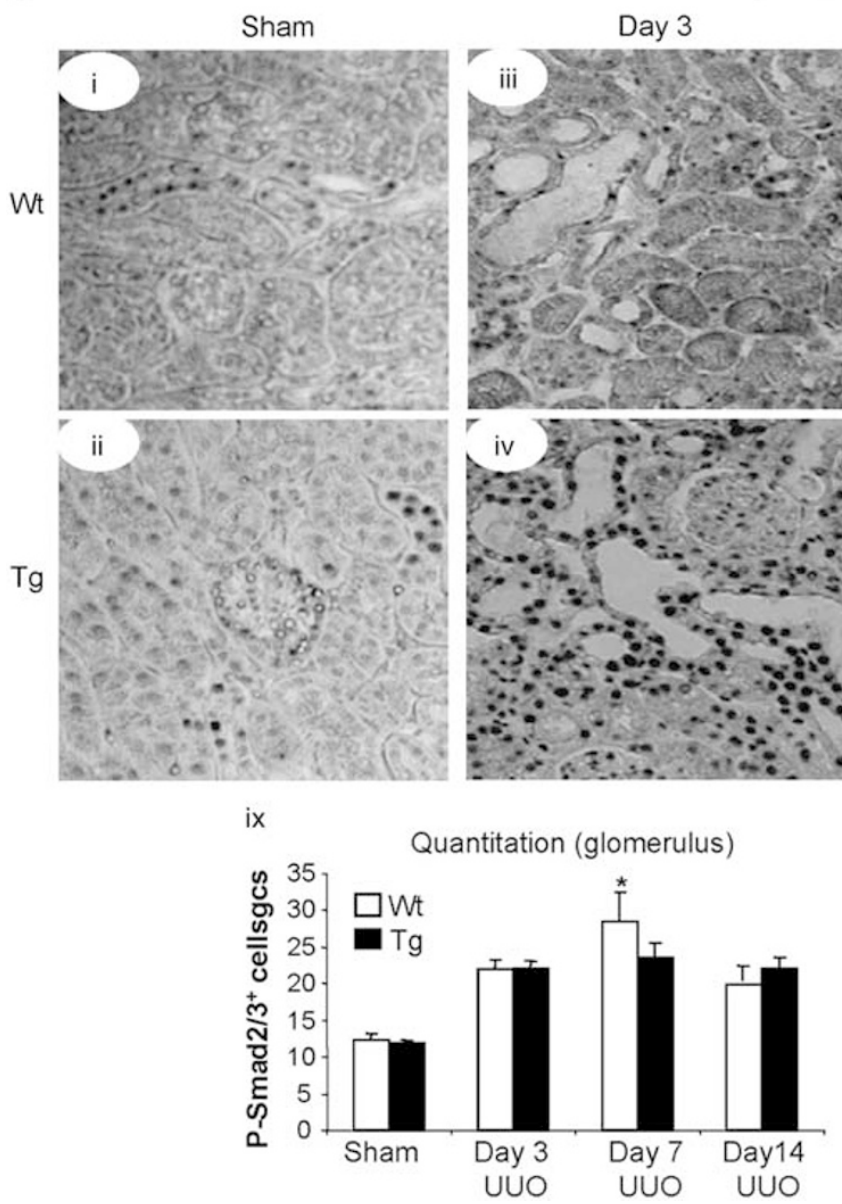

Phospho-Smad2/3 expression
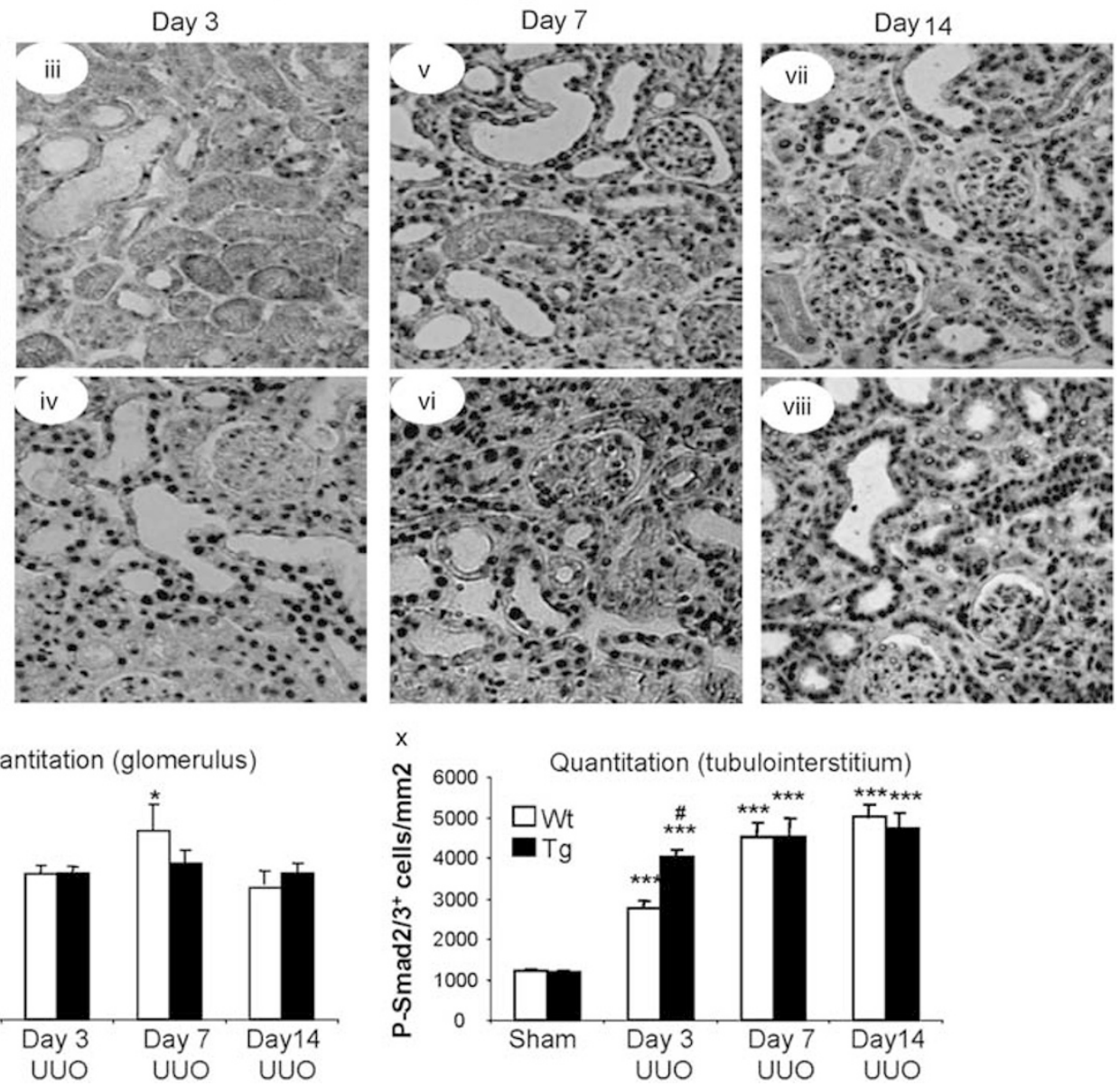

Figure 9 Continued.

that some, but not all studies, show a close link between the elevation of CRP and disease progression. ${ }^{3,17-19,45,46}$

The relationship between the inflammatory response and fibrosis is complex and of major importance in the pathogenesis of CKD. Of course, findings from this study did not provide clear evidence for the cause-and-effect relationship between CRP and progressive renal injury and outcomes from this study might have limited relevance to humans with kidney disease, but they do suggest that human CRP is not only a biomarker for progression of kidney disease but might also be a mediator of the disease. It is clear that in the CRPtg mouse, human CRP hastens the pace of renal inflammation and fibrosis following the initial kidney injury. This occurs in association with increased endogenous CRP expression and interaction with its receptors, thereby promoting activation of both TGF- $\beta /$ Smad signaling and NF- $\kappa \mathrm{B}$ signaling pathways. A similar interaction may likely operate in patients with CKD.

\section{ACKNOWLEDGEMENT}

This work was supported by grants from Research Grant Council of Hong Kong (RGC GRF 768207 and 767508, CUHK5/CRF/09 to HYL).

\section{DISCLOSURE/CONFLICT OF INTEREST}

The authors declare no conflict of interest.

1. Pecoits-Filho R, Sylvestre LC, Stenvinkel P. Chronic kidney disease and inflammation in pediatric patients: from bench to playground. Pediatr Nephrol 2005;20:714-720.

2. Kalantar-Zadeh $\mathrm{K}$, Stenvinkel $\mathrm{P}$, Pillon $\mathrm{L}$, et al. Inflammation and nutrition in renal insufficiency. Adv Ren Replace Ther 2003;10: 155-169.

3. Stenvinkel $P$, Lindholm B. C-reactive protein in end-stage renal disease: are there reasons to measure it? Blood Purif 2005;23:72-78.

4. Szalai AJ, McCrory MA. Varied biologic functions of C-reactive protein: lessons learned from transgenic mice. Immunol Res 2002;26:279-287.

5. Ross R. Atherosclerosis-an inflammatory disease. N Engl J Med 1999;340:115-126.

6. Hansson GK. Inflammation, atherosclerosis, and coronary artery disease. N Engl J Med 2005;352:1685-1695.

7. Paul A, Ko KW, Li L, et al. C-reactive protein accelerates the progression of atherosclerosis in apolipoprotein E-deficient mice. Circulation 2004;109:647-655

8. Danenberg HD, Szalai AJ, Swaminathan RV, et al. Increased thrombosis after arterial injury in human C-reactive protein-transgenic mice. Circulation 2003;108:512-515.

9. Teoh H, Quan A, Lovren F, et al. Impaired endothelial function in Creactive protein overexpressing mice. Atherosclerosis 2008;201: 318-325.

10. Pasceri V, Willerson JT, Yeh ET. Direct proinflammatory effect of Creactive protein on human endothelial cells. Circulation 2000;102:2165-2168. 
11. Wadham C, Albanese N, Roberts J, et al. High-density lipoproteins neutralize C-reactive protein proinflammatory activity. Circulation 2004;109:2116-2122.

12. Verma S, Li SH, Badiwala MV, et al. Endothelin antagonism and interleukin- 6 inhibition attenuate the proatherogenic effects of $C$ reactive protein. Circulation 2002;105:1890-1896.

13. Han $\mathrm{KH}$, Hong $\mathrm{KH}$, Park $\mathrm{JH}$, et al. C-reactive protein promotes monocyte chemoattractant protein-1-mediated chemotaxis through upregulating CC chemokine receptor 2 expression in human monocytes. Circulation 2004;109:2566-2571.

14. Pasceri V, Cheng JS, Willerson JT, et al. Modulation of C-reactive protein-mediated monocyte chemoattractant protein-1 induction in human endothelial cells by anti-atherosclerosis drugs. Circulation 2001;103:2531-2534.

15. Zhang $R$, Zhang $Y Y$, Huang $X R$, et al. C-reactive protein promotes cardiac fibrosis and inflammation in angiotensin Il-induced hypertensive cardiac disease. Hypertension 2010;55:953-960.

16. Schwedler SB, Guderian F, Dammrich J, et al. Tubular staining of modified C-reactive protein in diabetic chronic kidney disease. Nephrol Dial Transplant 2003;18:2300-2307.

17. Stuveling EM, Hillege HL, Bakker SJ, et al. C-reactive protein is associated with renal function abnormalities in a non-diabetic population. Kidney Int 2003;63:654-661.

18. Stenvinkel $P$, Heimburger $O$, Paultre $F$, et al. Strong association between malnutrition, inflammation, and atherosclerosis in chronic renal failure. Kidney Int 1999;55:1899-1911.

19. Muntner $P$, Hamm LL, Kusek JW, et al. The prevalence of nontraditional risk factors for coronary heart disease in patients with chronic kidney disease. Ann Intern Med 2004;140:9-17.

20. Ciliberto G, Arcone R, Wagner EF, et al. Inducible and tissue-specific expression of human C-reactive protein in transgenic mice. EMBO 1987;6:4017-4022.

21. Szalai AJ, van Ginkel FW, Dalrymple SA, et al. Testosterone and IL-6 requirements for human C-reactive protein gene expression in transgenic mice. J Immunol 1998;160:5294-5299.

22. Wang W, Huang XR, Li AG, et al. Signaling mechanism of TGF-beta1 in prevention of renal inflammation: role of Smad7. J Am Soc Nephrol 2005;16:1371-1383.

23. Huang XR, Chung AC, Wang XJ, et al. Mice overexpressing latent TGFbeta1 are protected against renal fibrosis in obstructive kidney disease. Am J Physiol Renal Physiol 2008;295:F118-F127.

24. Chung $A C$, Huang $X R$, Zhou $L$, et al. Disruption of the Smad7 gene promotes renal fibrosis and inflammation in unilateral ureteral obstruction (UUO) in mice. Nephrol Dial Transplant 2009:24:1443-1454.

25. Chung AC, Zhang $\mathrm{H}$, Kong $\mathrm{YZ}$, et al. Advanced glycation end-products induce tubular CTGF via TGF-beta-independent Smad3 signaling. J Am Soc Nephrol 2010;21:249-260.

26. Lan HY, Mu W, Nikolic-Paterson DJ, et al. A novel, simple, reliable, and sensitive method for multiple immunoenzyme staining: use of microwave oven heating to block antibody crossreactivity and retrieve antigens. J Histochem Cytochem 1995;43:97-102.

27. Xing $D$, Hage $F G$, Chen $Y F$, et al. Exaggerated neointima formation in human C-reactive protein transgenic mice is IgG Fc receptor type I (Fc\\{gammal\}RI)-dependent. Am J Pathol 2008;172:22-30.

28. Mold C, Du Clos TW. C-reactive protein increases cytokine responses to Streptococcus pneumoniae through interactions with Fc gamma receptors. J Immunol 2006:176:7598-7604.
29. Verma S, Badiwala MV, Weisel RD, et al. C-reactive protein activates the nuclear factor-kappaB signal transduction pathway in saphenous vein endothelial cells: implications for atherosclerosis and restenosis. J Thorac Cardiovasc Surg 2003;126:1886-1891.

30. Liu Y. Renal fibrosis: new insights into the pathogenesis and therapeutics. Kidney Int 2006;69:213-217.

31. Chen $Y$, Wang J, Yao $Y$, et al. CRP regulates the expression and activity of tissue factor as well as tissue factor pathway inhibitor via NF-kappaB and ERK 1/2 MAPK pathway. FEBS Lett 2009;583: 2811-2818.

32. Wang W, Koka V, Lan HY. Transforming growth factor-beta and Smad signalling in kidney diseases. Nephrology (Carlton) 2005; 10:48-56.

33. Fogo AB. Mechanisms of progression of chronic kidney disease. Pediatr Nephrol 2007;22:2011-2022.

34. Lan HY, Mu W, Tomita $\mathrm{N}$, et al. Inhibition of renal fibrosis by gene transfer of inducible Smad7 using ultrasound-microbubble system in rat UUO model. J Am Soc Nephrol 2003;14:1535-1548.

35. Ballou SP, Lozanski G. Induction of inflammatory cytokine release from cultured human monocytes by C-reactive protein. Cytokine 1992;4:361-368.

36. Liang YJ, Shyu KG, Wang BW, et al. C-reactive protein activates the nuclear factor-kappaB pathway and induces vascular cell adhesion molecule-1 expression through CD32 in human umbilical vein endothelial cells and aortic endothelial cells. J Mol Cell Cardiol 2006;40:412-420.

37. Bottinger EP, Bitzer M. TGF-beta signaling in renal disease. J Am Soc Nephrol 2002;13:2600-2610.

38. Schnaper HW, Hayashida T, Poncelet AC. It's a Smad world: regulation of TGF-beta signaling in the kidney. J Am Soc Nephrol 2002;13: $1126-1128$.

39. Terada Y, Hanada S, Nakao A, et al. Gene transfer of Smad7 using electroporation of adenovirus prevents renal fibrosis in postobstructed kidney. Kidney Int 2002;61:94-98.

40. Li JH, Zhu HJ, Huang XR, et al. Smad7 inhibits fibrotic effect of TGFBeta on renal tubular epithelial cells by blocking Smad2 activation. J Am Soc Nephrol 2002;13:1464-1472.

41. Hou CC, Wang W, Huang XR, et al. Ultrasound-microbubble-mediated gene transfer of inducible Smad7 blocks transforming growth factorbeta signaling and fibrosis in rat remnant kidney. Am J Pathol 2005;166:761-771.

42. Sato M, Muragaki Y, Saika S, et al. Targeted disruption of TGF-beta1/ Smad3 signaling protects against renal tubulointerstitial fibrosis induced by unilateral ureteral obstruction. J Clin Invest 2003;112:1486-1494.

43. Li JH, Lv KY, Li HY, et al. Suppressed acute phase response to LPSinduced hepatic injury in Smad3-deficient mice. Mol Immunol 2009;46:362-365.

44. Taylor AW, Ku NO, Mortensen RF. Regulation of cytokine-induced human C-reactive protein production by transforming growth factorbeta. J Immunol 1990;145:2507-2513.

45. Zacho J, Tybjaerg-Hansen A, Jensen JS, et al. Genetically elevated Creactive protein and ischemic vascular disease. N Engl J Med 2008;359:1897-1908.

46. Elliott $\mathrm{P}$, Chambers JC, Zhang W, et al. Genetic Loci associated with $\mathrm{C}$ reactive protein levels and risk of coronary heart disease. JAMA 2009;302:37-48. 